\title{
Kinetic Analysis of the Rebek Self-Replicating System: Is There a Controversy?
}

\author{
David N. Reinhoudt,* Dmitry M. Rudkevich, and Feike de Jong
}

Contribution from the Laboratory of Organic Chemistry, University of Twente, P.O. Box 217, 7500 AE Enschede, The Netherlands

Received January 30, $1996^{\otimes}$

\begin{abstract}
The Rebek self-replication reaction of $\mathbf{1}$ and 2, catalyzed by complexation of both reactants to the resulting product 3 (Tjivikua, T.; et al. J. Am. Chem. Soc. 1990, 112, 1249-1250. Nowick, J. S.; et al. J. Am. Chem. Soc. 1991, 113, 8831-8839. Wintner, E. A.; et al. Acc. Chem. Res. 1994, 27, 198-203. Conn, M. M.; et al. J. Am. Chem. Soc. 1994, 116, 8823-8824), and related work of Menger et al. (Menger, F. M.; et al. J. Am. Chem. Soc. 1994, 116, 3613-3614. Menger, F. M.; et al. J. Org. Chem. 1995, 60, 2870-2878) have been reinvestigated. On the basis of our experiments with the same systems and comparing the absolute rates of different (model) reactions, we have identified five pathways of the reaction between $\mathbf{1}$ and $\mathbf{2}$ in the presence of template 3: background $\left(k_{1}=0.035 \mathrm{M}^{-1}\right.$ $\left.\min ^{-1}\right)$, preassociative $\left(k_{2}=0.0044 \mathrm{~min}^{-1}\right)$, termolecular $\left(k_{3}=0.030 \mathrm{~min}^{-1}\right)$, and two bimolecular $\left(k_{4}=0.130 \mathrm{M}^{-1}\right.$ $\left.\min ^{-1}, k_{5}=0.020 \mathrm{M}^{-1} \mathrm{~min}^{-1}\right)$. A general kinetic model for self-replicating reactions has been used to analyze the Rebek-Menger controversy. We conclude that self-replication as defined by Rebek et al. operates in this system; other pathways obscure the simple picture of a ternary complex as the only complex that leads to the rate enhancement and one of those (bimolecular) pathways is that proposed by Menger et al. Our results show that when $\mathbf{1}$ and $\mathbf{2}$ are complexed to $\mathbf{3}$ in a termolecular complex, the rate of reaction between $\mathbf{1}$ and $\mathbf{2}$ is 6.8 times $\left(k_{3} / k_{2}\right)$ faster than when $\mathbf{3}$ is formed from the bimolecular complex of $\mathbf{1}$ and $\mathbf{2}$, and this rate enhancement factor represents the efficiency of template 3 in the self-replication process.
\end{abstract}

\section{Introduction}

When von Kiedrowski showed that a protected hexadeoxynucleotide catalyzes its own formation from the complementary trideoxynucleotides, the concept of artificial "self-replicating" systems was established. ${ }^{1}$ The initial work dealt with (deoxy)nucleotide chemistry, but recently also other classes of molecules that have recognition sites have received considerable attention. ${ }^{1,2}$ Almost by definition such studies are complicated by the different complexation equilibria between reactants and products. In particular, the strong tendency of the catalyst to dimerize because of its complementary binding sites does lead to "inactivation" of the catalyst (product) when the concentration increases. This means that the intuitive expectation that the rate of product formation in time should increase is often not observed. ${ }^{1,2}$ Background and preassociative reaction pathways further obscure the actual self-replicating pathway. Even the precise definition of self-replication is often unclear. For the further discussion we define self-replication as autocatalysis by a reaction product which is able to recognize at least two individual reactants with a high degree of selectivity. There are two ways in which the product can catalyze the reaction, viz., by preassociation of the reactants with the product, which enhances their effective molarity, and/or by stabilizing an intermediate or a transition state leading to product.

One self-replicating system, depicted in Scheme 1, has recently received considerable attention, and it has become a subject of controversy over the last two years. ${ }^{3-7}$ The reaction

${ }^{\otimes}$ Abstract published in Advance ACS Abstracts, June 15, 1996

(1) (a) von Kiedrowski, G. Angew. Chem., Int. Ed. Engl. 1986, 25, 932935. (b) von Kiedrowski, G.; Wlotzka, B.; Helbing, J.; Matzen, M.; Jordan, S. Angew. Chem., Int. Ed. Engl. 1991, 30, 423-426. (c) Terfort, A.; von Kiedrowski, G. Angew. Chem., Int. Ed. Engl. 1992, 31, 654-656. (d) Sievers, D.; von Kiedrowski, G. Nature 1994, 369, 221-224.

(2) For timely reviews on the problem, see: (a) Hoffmann, S. Angew. Chem., Int. Ed. Engl. 1992, 31, 1013-1016. (b) Orgel, L. E. Acc. Chem. Res. 1995, 28, 109-118. comprises the formation of a secondary amide bond by reaction of a primary amine with an activated (pentafluorophenyl) ester. Rebek et al. ${ }^{3}$ reported that, when the reactants have complementary recognition sites (ester $\mathbf{1}$ and amine 2), the resulting product amide $\mathbf{3}$ can act as a template and catalyzes its own formation. The proper geometry of the termolecular complex of the product $\mathbf{3}$ and the two reactants $\mathbf{1}$ and $\mathbf{2}$ favors the amide

(3) (a) Tjivikua, T.; Ballester, P.; Rebek, J., Jr. J. Am. Chem. Soc. 1990, 112, 1249-1250. (b) Nowick, J. S.; Feng, Q.; Tjivikua, T.; Ballester, P.; Rebek, J., Jr. J. Am. Chem. Soc. 1991, 113, 8831-8839. Evidence for selfreplicative catalysis came from a $c a$. $40-70 \%$ inhancement of the initial rate when $(0.2-0.5$ equiv of ) amide 3 was added to the reaction mixture (at $1.65,8.2$, and $16.5 \mathrm{mM}$ concentrations). The $N$-methylated analog of 1 showed a ca. 6.5-fold decrease of the background rate, while 2,6bis(acetylamino)pyridine which is complementary to Kemp's imide moiety of ester 1 inhibited the reaction as well; the rate dropped from 0.01 to 0.0049

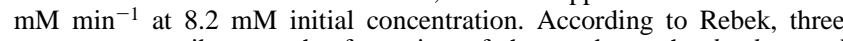
processes contribute to the formation of the product: the background bimolecular reaction, the base-paired bimolecular reaction, and the termolecular template-catalyzed reaction (via a termolecular complex). For a short overview of Rebek's work, see: Wintner, E. A.; Conn, M. M.; Rebek, J., Jr. Acc. Chem. Res. 1994, 27, 198-203.

(4) Menger, F. M.; Eliseev, A. V.; Khanjin, N. A. J. Am. Chem. Soc. 1994, 116, 3613-3614. It was shown that primary amides (e.g., acetamide, 2-naphthamide) and secondary $N$-methylpropionamide also catalyze the reaction between $\mathbf{1}$ and $\mathbf{2}$. The authors stated that, since Rebek's template $\mathbf{3}$ is an amide itself, the reaction is not self-replicating but simply amidecatalyzed.

(5) Menger, F. M.; Eliseev, A. V.; Khanjin, N. A.; Sherrod, M. J. J. Org. Chem. 1995, 60, 2870-2878. Although both Rebek et al. and Menger et al. have used strong arguments defending their mechanisms, some (essential) differences in their experimental approaches should be pointed out. Firstly, Rebek and Menger used (in most of the cases) different initial concentration regimes. While Rebek's experiments were performed at 16.5 $\mathrm{mM}$ as a highest concentration, Menger et al. published their amide catalysis at $30 \mathrm{mM}$ concentration. At the same time, $N$-methylpropionamide when tested at $8 \mathrm{mM}$ failed to accelerate the reaction. This point is important since whole the process involves hydrogen-bonding aggregation and therefore is (highly) concentration dependent. In addition, at higher concentrations, general base catalysis by (simple) amides cannot be excluded. ${ }^{8}$ Secondly, Rebek et al. used the HPLC technique and Menger et al. employed NMR spectroscopy. Thirdly, Menger et al. never tested Rebek's model compounds (e.g., 6-8). 


\section{Scheme 1}
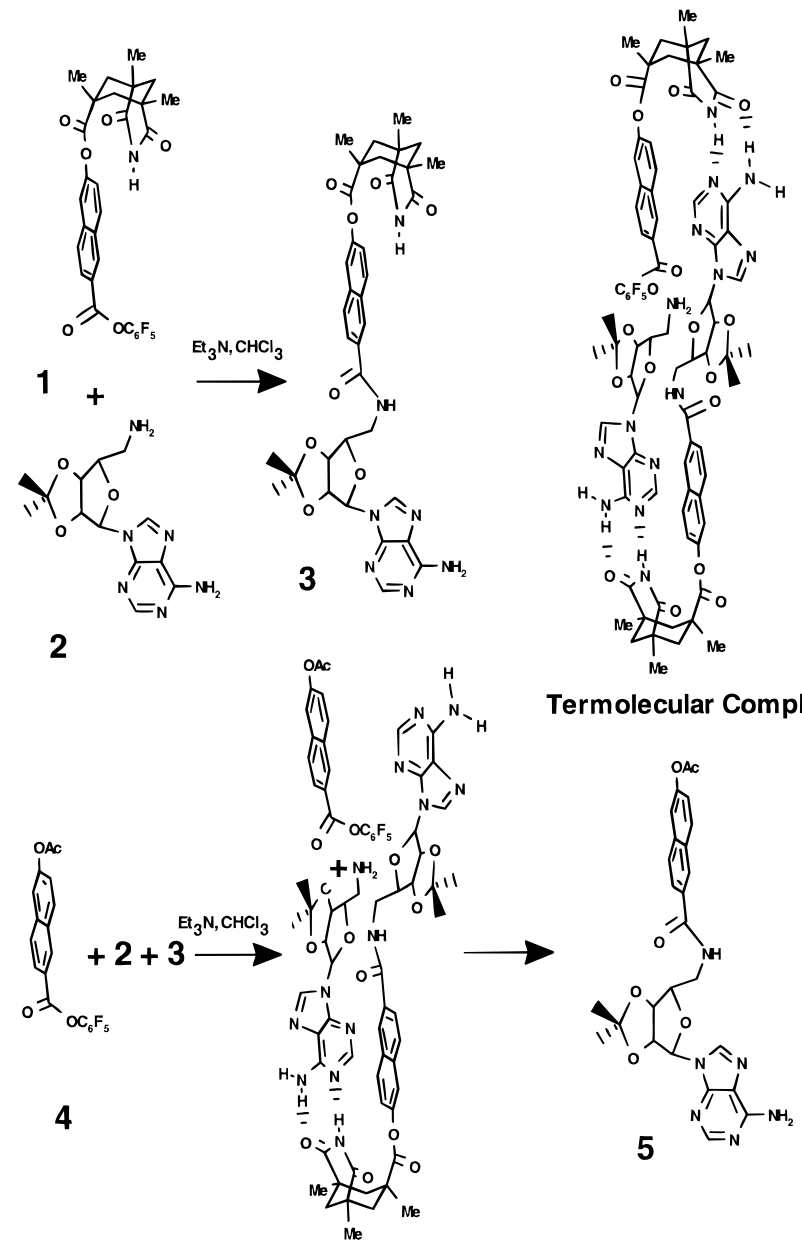

Termolecular Complex

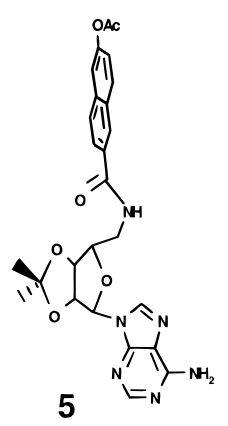

bond formation. In two recent papers Menger et al. ${ }^{4,5}$ have reported, on the basis of a series of their own independent experiments with the same system, that another mechanism might also explain the observed rate enhancement. They postulated either "simple" amide catalysis or a pathway that involves a bimolecular reaction between the ester (1 or $\mathbf{4})$ and the bimolecular complex $(\mathbf{2} \cdot \mathbf{3})$ of the product 3 with the amine 2 (Scheme 1). In this case one recognition site in the product would be sufficient to explain the observed rate acceleration of the amide formation. Menger et al. hypothesized that the secondary trans-amide fragment in the product might play a role in stabilizing the tetrahedral intermediate or assist in the rate-determining step of pentafluorophenol release. Amides are known to (auto)accelerate aminolysis by stabilizing a tetrahedral zwitterionic intermediate by hydrogen bonding between the zwitterionic $\mathrm{NH}$ and $\mathrm{C}=\mathrm{O}$ of the amide group. ${ }^{8}$

In this paper, we report our results with this self-replicating system based on our independent experiments and a kinetic analysis of the process in which all relevant equilibria and

(6) In a later communication, Rebek et al. demonstrated that not all amides do accelerate the reaction of $\mathbf{1}$ and $\mathbf{2}$. Thus, model compounds $6-8$ which have the structural fragments of template $\mathbf{3}$, namely, trans-secondary amide, Kemp's imide, and adenosine, respectively, show no catalysis in the reaction between $\mathbf{1}$ and $\mathbf{2}$ when the reactions are performed at $2.2 \mathrm{mM}$ initial concentration. Since there is no primary amide function present in the reaction mixture, acetamide and 2-naphthamide were rejected as incorrect models. See: Conn, M. M.; Wintner, E. A.; Rebek, J., Jr. J. Am. Chem. Soc. 1994, 116, 8823-8824.

(7) Wintner, E. A.; Tsao, B.; Rebek, J., Jr. J. Org. Chem. 1995, 60, 79978001 .

(8) See, for example: (a) Titskii, G. D.; Litvinenko, L. M. Zh. Gen. Chem. USSR (Russ. Ed.) 1970, 40, 2680-2688. (b) Su, C.-W.; Watson, J. J. Am. Chem. Soc. 1974, 96, 1854-1857.

\section{Chart 1}
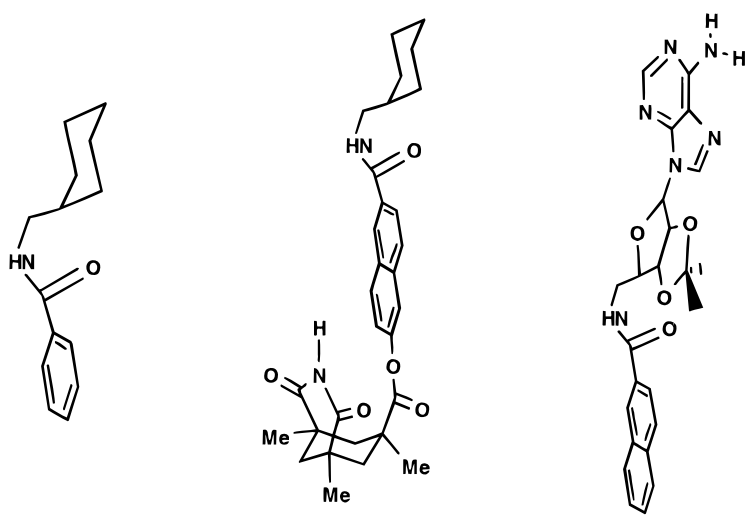

6

7

reactions are incorporated. Despite all discussions we feel that the kinetics of the reactions involved has not received the attention it deserves. Although kinetics cannot prove a mechanism, proper kinetic data can help to unravel the different pathways that lead to product at different concentrations of reagents, products, and additives.

\section{Results and Discussion}

First, we have synthesized the amines, esters, and "templates" which may have one or two binding sites (including a novel adenosine derivative) and which are needed for the evaluation of the basic reaction between the pentafluorophenyl ester $\mathbf{1}$ and the $5^{\prime}$-aminoadenosine derivative $\mathbf{2}$ in the presence of their reaction product (the template) $\mathbf{3}$.

Second, we have measured by ${ }^{1} \mathrm{H}$ NMR spectroscopy the rates of product formation for different reactants in the absence and in the presence of $\mathbf{3}$ and of other additives.

Third, we have developed a kinetic scheme in which all relevant reactions are included together with the complexation equilibria in which up to four components participate. From this model and the experimental data on product formation we have calculated the rate constants of five different pathways that may lead to product. With these rate constants and initial compositions of the different reaction mixtures we have calculated the individual contributions of these five pathways to the product formation. The same parameters have also been used to calculate the overall product formation as a function of time.

Finally, we have compared our results with some relevant experiments described by the groups of Rebek and Menger.

Synthesis. Studying the self-replicating scheme, we first prepared reactants which possess hydrogen-bonding sites. Thus, pentafluorophenyl ester $\mathbf{1}^{3}$ with Kemp's triacid imide moiety and $5^{\prime}$-aminoadenosine $2^{9}$ were synthesized according to known procedures. Template $\mathbf{3}$ was prepared from the corresponding acid chloride and $5^{\prime}$-aminoadenosine $2{ }^{3}$ and also isolated in $92 \%$ yield after the reaction between $\mathbf{1}$ and $\mathbf{2}$. The nonbinding ester $4^{5}$ (also called the "crippled" ester or reactant) was synthesized and used as a substrate for the model reaction with $5^{\prime}$-aminoadenosine 2. Crippled templates $6-\mathbf{8}^{7}$ (Chart 1 ) which only partly have the structural fragments of template $\mathbf{3}$, namely, the trans-secondary amide in 6, Kemp's imide in 7, and the adenosine residue in $\mathbf{8}$, respectively, were synthesized in order to study their influence on the reaction between esters $\mathbf{1}$ and/or $\mathbf{4}$ and amine 2. Finally, in addition to crippled ester $\mathbf{4}$, we have

(9) Kolb, M.; Danzin, C.; Barth, J.; Claverie, N. J. Med. Chem. 1982, 25, 550-556. For the review on Mitsunobu reaction see: Mitsunobu, O. Synthesis 1981, 1-28. 


\section{Scheme $2^{a}$}

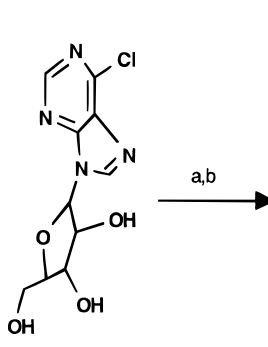

10

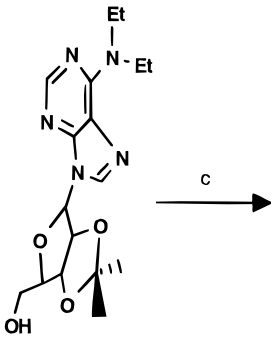

11

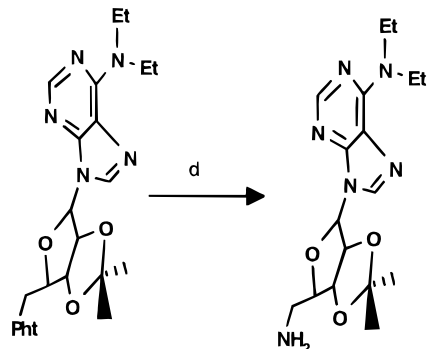

12
${ }^{a}$ Conditions: (a) acetone, $p$-TsOH, rt; (b) $\mathrm{HNEt}_{2}$, EtOH, reflux; (c) phthalimide, DAC, $\mathrm{PPh}_{3}$, THF, rt; (d) $\mathrm{H}_{2} \mathrm{NNH}_{3} \mathrm{OH}, \mathrm{EtOH}$, reflux.

synthesized the novel crippled 5'-aminoadenosine 9 in which the adenyl amino group bears two ethyl moieties and therefore is unable to form hydrogen bonds (Scheme 2). Isopropylidene riboside 11 was synthesized from the corresponding 6-chloropurine riboside $\mathbf{1 0}$ by reaction with acetone in the presence of $p$-toluenesulfonic acid monohydrate ${ }^{10}$ followed by aminolysis with diethylamine in refluxing ethanol. Subsequent Mitsunobu reaction with triphenylphosphine, phthalimide, and diethyl azodicarboxylate (DAC) in THF afforded the corresponding phthalimide derivative $\mathbf{1 2}$ which after subsequent refluxing with hydrazine hydrate in ethanol gave pure $\mathbf{9}$.

Kinetics Studies. All kinetic experiments were performed using ${ }^{1} \mathrm{H}$ NMR spectroscopy in $\mathrm{CDCl}_{3}$ containing 4 equiv of $\mathrm{Et}_{3} \mathrm{~N}$ as a base, at $25{ }^{\circ} \mathrm{C} .{ }^{11}$ Reactions of amine $\mathbf{2}$ and pentafluorophenyl esters $\mathbf{1}$ and $\mathbf{4}$ were studied at 8.25, 16.5, 30 , and (in one case) $50 \mathrm{mM}$ concentrations. In experiments where templates, crippled templates, or other additives were used, either 0.5 or 1.0 mol equiv was employed. Generally, ribose signals were monitored, but in some cases naphthyl signals were additionally employed. Evaporative loss was excluded. All reactions were followed until $\geq 95 \%$ conversion. The reaction product amide $\mathbf{3}$ was also isolated in $92 \%$ yield on a preparative scale after reaction of $\mathbf{1}$ and $\mathbf{2}$. We have never observed byproducts, and pentafluorophenyl ester hydrolysis was not detected. In addition, we used toluene as an internal standard for the determination of conversion. In order to compare our results with those published in the literature, the "initial rates" were defined as the slope of the conversion $v s$

(10) Hampton, A. J. Am. Chem. Soc. 1961, 83, 3640-3645.

(11) Both Rebek et al. and Menger et al. reported no specific purification of $\mathrm{CDCl}_{3}$, and therefore we have used for all our experiments spectroscopic quality $\mathrm{CDCl}_{3}$ (Merck) which was passed through $\mathrm{Al}_{2} \mathrm{O}_{3}$ and stored over molecular sieves before use. It should be realized that small amounts of protic solvents $\left(\mathrm{H}_{2} \mathrm{O}\right.$, EtOH, phenols, etc.) might influence the absolute values of association constants. However, we needed values of association constants under reaction conditions, and therefore those values were determined in the same $\mathrm{CDCl}_{3}$ which was used in all kinetic experiments. Rebek et al. ${ }^{3}$ observed, in addition to broad NH resonances, overlapping multiplets which did not allow him to follow kinetics by ${ }^{1} \mathrm{H}$ NMR spectroscopy. In contrast, Menger et al. ${ }^{4,5}$ used both ${ }^{1} \mathrm{H}$ and ${ }^{19} \mathrm{~F}$ NMR techniques with reasonable accuracy. We also observed sharp and wellresolved ${ }^{1} \mathrm{H}$ NMR spectra at $8.25,16.5$, and $30 \mathrm{mM}$ concentrations.
Table 1. Initial Rates of the Reaction between the Ester 1 (4) and the Amine 2 (9) in the Absence and Presence of Additives in $\mathrm{CDCl}_{3}$ at Different Initial Concentrations ${ }^{a}$

\begin{tabular}{|c|c|c|c|}
\hline $\begin{array}{c}\text { reactants } \\
(\text { concn, } \mathrm{mM})\end{array}$ & $\begin{array}{c}\text { additive } \\
\text { (concn, } \mathrm{mM} \text { ) }\end{array}$ & $\begin{array}{l}\text { obsd } \\
\text { initial rate }\end{array}$ & $\begin{array}{l}\text { relative rate } \\
\text { (\% of blank) }\end{array}$ \\
\hline $\mathbf{1}, \mathbf{2}(8.25)$ & none & 1.4 & 100 \\
\hline $\mathbf{1}, \mathbf{2}(8.25)$ & $3(4.12)$ & 2.0 & 143 \\
\hline $\mathbf{1}, \mathbf{2}(8.25)$ & $6(4.12)$ & 1.2 & 86 \\
\hline $\mathbf{1}, \mathbf{2}(16.5)$ & none & 4.1 & 100 \\
\hline $\mathbf{1}, \mathbf{2}(16.5)$ & $3(8.25)$ & 5.7 & 139 \\
\hline $\mathbf{1}, \mathbf{2}(16.5)$ & $3(11.55)$ & 5.9 & 144 \\
\hline $\mathbf{1}, \mathbf{2}(16.5)$ & $3(16.5)$ & 6.2 & 151 \\
\hline $\mathbf{1}, \mathbf{2}(16.5)$ & $6(8.25)$ & 4.2 & 102 \\
\hline $\mathbf{1}, \mathbf{2}(16.5)$ & $7(8.25)$ & 4.3 & 105 \\
\hline $\mathbf{1}, \mathbf{2}(16.5)$ & $8(8.25)$ & 3.7 & 90 \\
\hline 1, $2(30.0)$ & none & 12.9 & 100 \\
\hline $1,2(30.0)$ & $3(30.0)$ & 16.3 & 126 \\
\hline $1,2(50.0)$ & none & 47.0 & \\
\hline $4,2(16.5)$ & none & 0.6 & 100 \\
\hline $4,2(16.5)$ & $3(8.25)$ & 1.6 & 267 \\
\hline $4,2(16.5)$ & $3(16.5)$ & 1.8 & 300 \\
\hline $4,2(16.5)$ & $7(8.25)$ & 1.0 & 167 \\
\hline $4,2(30.0)$ & none & 3.3 & 100 \\
\hline $4,2(30.0)$ & $3(30.0)$ & 7.4 & 224 \\
\hline $\mathbf{1}, \mathbf{9}(16.5)$ & none & 0.9 & 100 \\
\hline $\mathbf{1}, \mathbf{9}(16.5)$ & $3(8.25)$ & 1.0 & 111 \\
\hline
\end{tabular}

${ }^{a}$ Determined by ${ }^{1} \mathrm{H}$ NMR at $25^{\circ} \mathrm{C} .{ }^{b}$ Data collected during the first $100 \mathrm{~min}$. Rates in $\mathrm{M} \cdot \mathrm{min}^{-1} \times 10^{5}( \pm 10 \%)$. Average rate over the first $100 \mathrm{~min}$.

time plot of the data collected during the first $100 \mathrm{~min}$ and were obtained by linear least squares analysis. ${ }^{12}$ Our results are presented in Table 1.

The initial rate for the reaction between $\mathbf{1}$ and $\mathbf{2}$ at $8.25 \mathrm{mM}$ is $0.014 \mathrm{mM} \mathrm{min}^{-1}$. In the presence of 0.5 equiv of template 3 the initial rate increased by $43 \%$ to $0.020 \mathrm{mM} \mathrm{min}^{-1}$. transAmide 6 when added to the reaction mixture slightly inhibited the process (initial rate $0.012 \mathrm{mM} \mathrm{min}^{-1}$ ). ${ }^{13}$ At $16.5 \mathrm{mM}$ the reaction of $\mathbf{1}$ and $\mathbf{2}$ produced $\mathbf{3}$ with an initial rate of 0.041

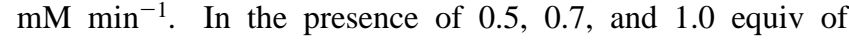
template 3 the initial rate increased by 39,44 , and $51 \%$, respectively $\left([3]=0.057,0.059\right.$, and $0.062 \mathrm{mM} \mathrm{min}^{-1}$, respectively). trans-Amide $\mathbf{6}$ as well as both individual ends of the template ( $\mathbf{7}$ and $\mathbf{8}$ ), when added to the reaction mixture, exhibited no catalytic activity; initial rates of $0.042,0.043$, and $0.037 \mathrm{mM} \mathrm{min}^{-1}$, respectively, were found.

The reaction between $\mathbf{2}$ and $\mathbf{4}$ at $16.5 \mathrm{mM}$ gave a surprisingly

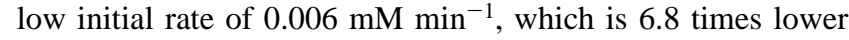
than for the reaction of $\mathbf{1}$ and $2 .{ }^{14}$ In the presence of 0.5 and 1.0 equiv of template 3 the initial rates of the reaction between 2 and 4 significantly increased to 0.016 and $0.018 \mathrm{mM} \mathrm{min}^{-1}$ which means 167 and 200\%(!) rate enhancement, respectively. However, the absolute rate values are still, respectively, 3.6 and 3.4 times lower than for the reaction of $\mathbf{1}$ and $\mathbf{2}$ catalyzed

(12) The initial rates from our experiments were calculated from conversion during the first 100 min. Rebek ${ }^{3}$ and Menger ${ }^{4}$ published the initial rates obtained from data collected after 60 and $40 \mathrm{~min}$, respectively. Strictly speaking, however, product formation is not linear in time, the deviation being dependent on concentration, the composition of the reaction mixture, and conversion. Therefore, the initial rates obtained from conversion vs time plots are generally somewhat lower than the "true" initial rates, i.e., $(\mathrm{d} P / \mathrm{d} t)_{t=0}$. We calculated the latter on the basis of corresponding kinetic equations from the composition of the mixtures at time $t=0$ and the determined reaction rate constants. Therefore, the initial rates can only be used to compare relative catalytic trends.

(13) Essentially higher than observed by Rebek et al. initial rates at 8.25 $\mathrm{mM}$ can be reasonably explained by hydrolysis which (for some reason) took place under their conditions (yielding only $c a$. $65 \%$ of 3 after $>1500$ $\min )$. See ref $3 b$.

(14) Menger et al. did not run the reaction $2+4$ at $16.5 \mathrm{mM}$ concentration but observed a $0.0018 \mathrm{mM} \mathrm{min}^{-1}$ rate at $8.2 \mathrm{mM}$ which is 5.6 times lower than the rate Rebek et al. reported at $8.2 \mathrm{mM}$ for the reaction between 1 and 2 . See ref 5 . 


\section{Scheme 3}

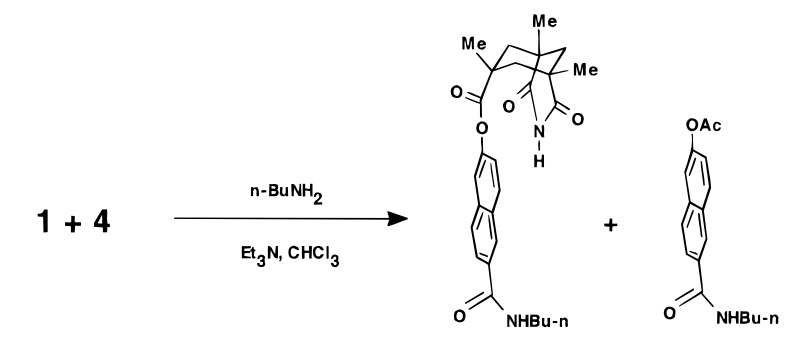

13

14

Ratio 1:1

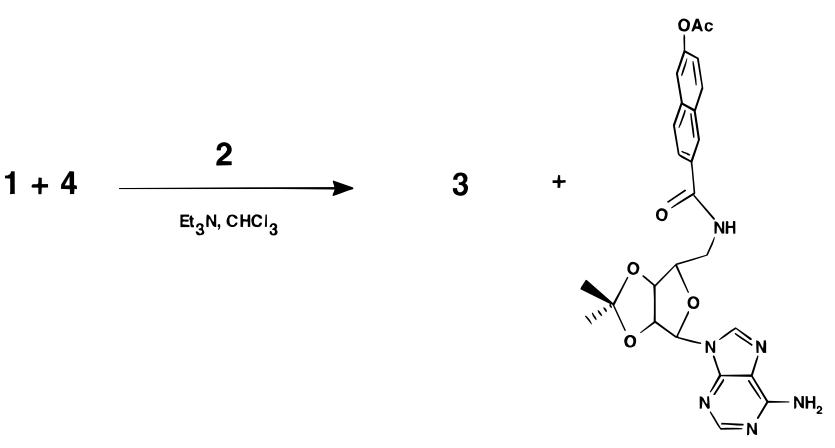

15

Ratio 4.5:1

by 3. The crippled template Kemp's imide 7, which can only form a complex with amine 2 , also accelerated the reaction with a rate of $0.010 \mathrm{mM} \mathrm{min}^{-1}$; this corresponds to a $67 \%$ increase. Similarly, we found that the reaction between ester $\mathbf{1}$ and the crippled 5'-aminoadenosine 9 is slow with an initial rate of 0.009 $\mathrm{mM} \min ^{-1}$ at $16.5 \mathrm{mM}$ concentration. Surprisingly, the addition of 0.5 equiv of template 3 did not (significantly) accelerate the reaction between $\mathbf{1}$ and $\mathbf{9}$; the rate was $0.010 \mathrm{mM} \mathrm{min}^{-1}$.

As expected, the reaction of $\mathbf{1}$ and $\mathbf{2}$ was considerably faster at higher concentrations with initial rate values of $0.129 \mathrm{mM}$ $\min ^{-1}$ at $30 \mathrm{mM}$ and $0.47 \mathrm{mM} \mathrm{min}^{-1}$ at $50 \mathrm{mM}$, respectively. The addition of 1.0 equiv of $\mathbf{3}$ gave, at $30 \mathrm{mM} \mathbf{1}$ and $\mathbf{2}$, a rate of $0.163 \mathrm{mM} \mathrm{min}^{-1}$ (increase of 26\%).

A mixture of $30 \mathrm{mM} 2$ and 4 reacted with an initial rate of $0.033 \mathrm{mM} \mathrm{min} \mathrm{m}^{-1}$ to yield $\mathbf{5}$. The addition of 1.0 equiv of $\mathbf{3}$ resulted in an initial rate of formation of 5 of $0.074 \mathrm{mM} \mathrm{min}^{-1}$ (increase of 124\%). We have eliminated the possibility that the reactivities of the pentafluorophenyl esters 1 and 4 might be different. A competition experiment utilizing equimolecular quantities of $n$-butylamine and of both esters 1 and 4 in $\mathrm{CDCl}_{3}$ with $1 \% \mathrm{Et}_{3} \mathrm{~N}$ as a base showed no preference for one of the esters; the corresponding amides $\mathbf{1 3}$ and $\mathbf{1 4}$ were formed in a ratio of $c a$. 1:1 (Scheme 3). The analogous competition experiment with equimolecular quantities of the aminoadenosine 2 and of the esters 1 and 4 in $\mathrm{CDCl}_{3}$ with $1 \% \mathrm{Et}_{3} \mathrm{~N}$ as a base exhibited a preference for the ester which has Kemp's imide moiety (1). The corresponding amides 3 and $\mathbf{1 5}$ were formed in a ratio of $c a$. 4.5:1 (Scheme 3).

We conclude that esters $\mathbf{1}$ and $\mathbf{4}$ behave differently because ester 1 binds amine $\mathbf{2}$ and ester $\mathbf{4}$ does not. The base-paired bimolecular reaction is essentially faster and takes place when both reactants have recognition sites. ${ }^{15}$

Kinetic Modeling (see also the supporting information). Basically our model describes the reaction of ester 1 (E) and

(15) This is in agreement with Rebek's observation that the nonbinding $\mathrm{N}$-methylated analog of $\mathbf{1}$ showed a $\mathrm{ca}$. 6.5 -fold decrease of the background rate. In fact, Rebek used the latter reaction as the background reaction in his kinetic modeling. amine 2 (A) in the presence of template $\mathbf{3}(\mathrm{T})$. When either $\mathrm{E}$ or A has no hydrogen-bonding sites as in a number of model reactions described in this paper, we can simply incorporate these situations by taking the corresponding association constants as zero. Firstly, we consider a mixture containing an amine component A (equipped with a hydrogen-bonding site) and an ester component $\mathrm{E}$ (equipped with a complementary hydrogen-bonding site) in the presence of a template $\mathrm{T}$, being nonreactive, and bearing both the hydrogen-bonding sites. When we restrict the system to complexes composed of at most four species, ${ }^{16}$ the following equilibria become established:

$$
\begin{aligned}
& \mathrm{A}+\mathrm{E} \rightleftarrows \mathrm{A} \cdot \mathrm{E} \\
& \mathrm{A}+\mathrm{T} \rightleftarrows \mathrm{A} \cdot \mathrm{T} \\
& \mathrm{E}+\mathrm{T} \rightleftarrows \mathrm{E} \cdot \mathrm{T} \\
& \mathrm{A}+\mathrm{E} \cdot \mathrm{T} \rightleftarrows \mathrm{A} \cdot \mathrm{T} \cdot \mathrm{E} \\
& \mathrm{E}+\mathrm{A} \cdot \mathrm{T} \rightleftarrows \mathrm{A} \cdot \mathrm{T} \cdot \mathrm{E} \\
& \mathrm{T}+\mathrm{T} \rightleftarrows \mathrm{T} \cdot \mathrm{T} \\
& \mathrm{T} \cdot \mathrm{T} \rightleftarrows \mathrm{T}_{2} \\
& \mathrm{~A}+\mathrm{T} \cdot \mathrm{T} \rightleftarrows \mathrm{A} \cdot \mathrm{T} \cdot \mathrm{T}
\end{aligned}
$$

$K_{1} \quad \mathrm{E}+\mathrm{T} \cdot \mathrm{T} \rightleftarrows \mathrm{E} \cdot \mathrm{T} \cdot \mathrm{T}$

$K_{2} \quad \mathrm{~T}+\mathrm{T} \cdot \mathrm{T} \rightleftarrows \mathrm{T} \cdot \mathrm{T} \cdot \mathrm{T}$

$K_{3} \mathrm{~T} \cdot \mathrm{T} \cdot \mathrm{T} \rightleftarrows \mathrm{T}_{3}$

$K_{4} \quad \mathrm{E}+\mathrm{A} \cdot \mathrm{T} \cdot \mathrm{T} \rightleftarrows \mathrm{A} \cdot \mathrm{T} \cdot \mathrm{T} \cdot \mathrm{E}$

$K_{5} \quad \mathrm{~A}+\mathrm{E} \cdot \mathrm{T} \cdot \mathrm{T} \rightleftarrows \mathrm{A} \cdot \mathrm{T} \cdot \mathrm{T} \cdot \mathrm{E}$

$K_{8} \quad \mathrm{~T}+\mathrm{A} \cdot \mathrm{T} \cdot \mathrm{T} \rightleftarrows \mathrm{A} \cdot \mathrm{T} \cdot \mathrm{T} \cdot \mathrm{T}$

$K_{9} \quad \mathrm{~T}+\mathrm{E} \cdot \mathrm{T} \cdot \mathrm{T} \rightleftarrows \mathrm{E} \cdot \mathrm{T} \cdot \mathrm{T} \cdot \mathrm{T}$

$K_{10} \quad \mathrm{~T}+\mathrm{T} \cdot \mathrm{T} \cdot \mathrm{T} \rightleftarrows \mathrm{T} \cdot \mathrm{T} \cdot \mathrm{T} \cdot \mathrm{T}$

$K_{11}$
$K_{12}$
$K_{13}$
$K_{14}$
$K_{15}$
$K_{16}$
$K_{17}$
$K_{18}$

Rebek et al. ${ }^{3}$ used a dimerization constant for the template, and an association constant for the ternary complex; they are related to the above through

$$
\begin{array}{cc}
\mathrm{T}+\mathrm{T} \rightleftarrows \mathrm{T}_{2} & K_{6}=K_{8} K_{9} \\
\mathrm{~A}+\mathrm{E}+\mathrm{T} \rightleftarrows \mathrm{A} \cdot \mathrm{T} \cdot \mathrm{E} & K_{7}=K_{3} K_{4}=K_{2} K_{5}
\end{array}
$$

In general amine $\mathrm{A}$ reacts with ester $\mathrm{E}$ to give the product amide $\mathrm{P}$ (A, E, and $\mathrm{P}$ may have hydrogen-bonding group(s) or not; when $\mathrm{A}$ is $\mathbf{2}$ and $\mathrm{E}$ is $\mathbf{1}$, product $\mathrm{P}$ is template $\mathbf{3}$ ). When the equilibrated mixture is allowed to react, the following reactions have to be taken into account. Firstly, we define the background reaction as the bimolecular reaction between $\mathrm{A}$ and $\mathrm{E}$ in the case that these components would lack (or do not use) the hydrogen-bonding properties:

$$
\mathrm{A}+\mathrm{E} \rightarrow \mathrm{P} \quad k_{1}
$$

In addition to the background reaction, the bimolecular $\mathrm{A} \cdot \mathrm{E}$ complex may internally form product $\mathrm{P}$ :

$$
\mathrm{A} \cdot \mathrm{E} \rightarrow \mathrm{P} \quad k_{2}
$$

The termolecular complex $\mathrm{A} \cdot \mathrm{T} \cdot \mathrm{E}$ may also directly form product P through

$$
\mathrm{A} \cdot \mathrm{T} \cdot \mathrm{E} \rightarrow \mathrm{P} \cdot \mathrm{T} \quad k_{3}
$$

Furthermore, the possibility exists that the template activates the bonded substrate $A$ in components such as $A \cdot T$ for the bimolecular reaction with free $\mathrm{E}$ :

$$
\mathrm{E}+\mathrm{A} \cdot \mathrm{T} \rightarrow \mathrm{PT} \quad k_{4}
$$

The same reasoning as given above for the activated $A \cdot T$ fragment could in principle be given for $\mathrm{E} \cdot \mathrm{T}$ as well:

$$
\mathrm{A}+\mathrm{E} \cdot \mathrm{T} \rightarrow \mathrm{P} \cdot \mathrm{T} \quad k_{5}
$$

In order to calculate the concentrations of all species present before and during the reaction, association constant $K_{1}$ was determined by ${ }^{1} \mathrm{H}$ NMR spectroscopy in $\mathrm{CDCl}_{3}$ using Kemp's ester 1 and a nonreactive acetyladenosine, 16 (Figure 1). Since in our hands the imide $\mathrm{NH}$ proton, which was used as a probe

(16) The results show that, with the current set of parameters, the concentrations of species composed of four components are very low up to $50 \mathrm{mM}$ concentration. 

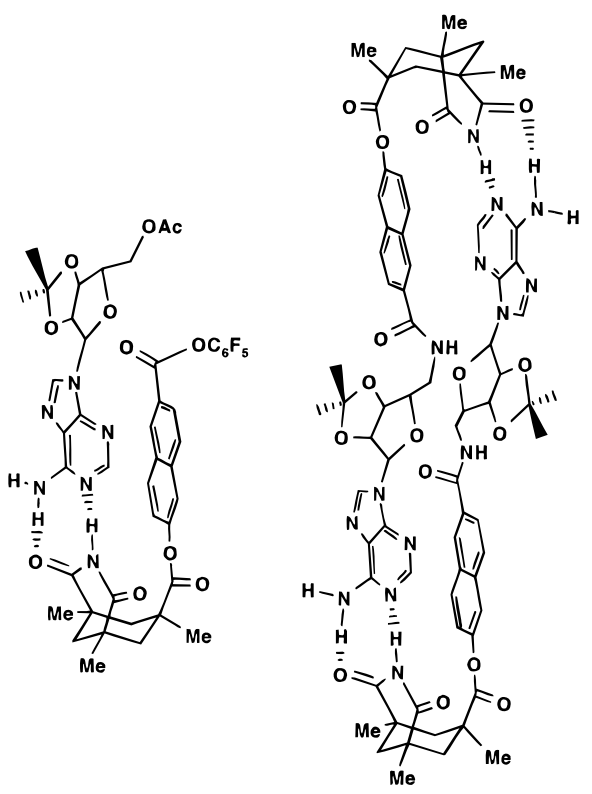

$1 \cdot 16$

$3_{2}\left(T_{2}\right)$

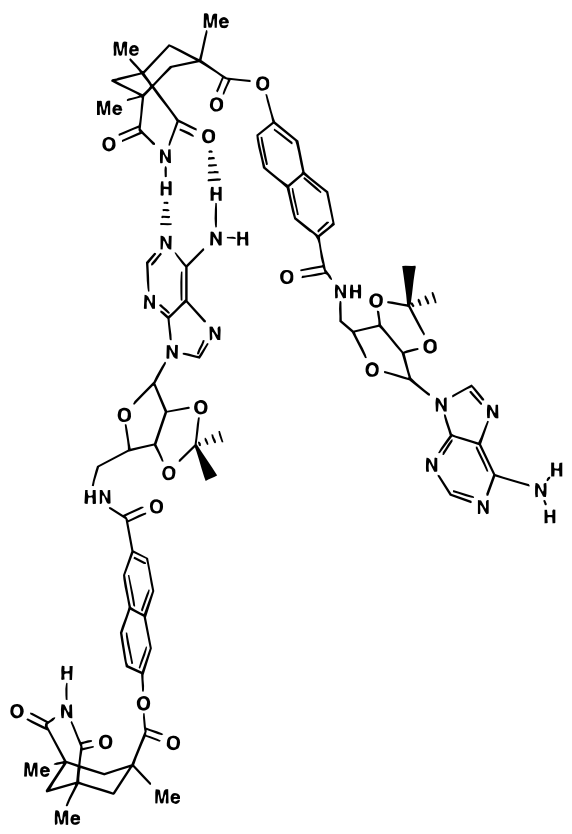

3.3 (T·T)

Figure 1. Base-paired complex of Kemp's ester $\mathbf{1}$ and acetyladenosine 16, and cyclic and linear dimers of template $\mathbf{3}$.

by Rebek et al., ${ }^{3,17}$ undergoes broadening upon titration, binding studies were performed using as a probe the relatively sharp adenine $\mathrm{NH}_{2}$ signal. In order to verify our results, the aromatic signals of the naphthalene moiety were employed in addition. The concentration of acetyladenosine 16 was kept constant at $1 \mathrm{mM}$ while up to 20 equiv of $\mathbf{1}$ was added in our titration experiments. Self-association of $\mathbf{1 6}$ will be low at this concentration. The results indeed show hydrogen bonding for Kemp's imide-adenine pair; a $K$ value of $100 \pm 10 \mathrm{M}^{-1}$ was obtained for $\mathbf{1}+\mathbf{1 6}$ which is in good agreement with the values found by Rebek et al. ${ }^{3}$ for similar compounds $\left(60-105 \mathrm{M}^{-1}\right)$.

(17) For typical examples from the Rebek group see: (a) Askew, B.; Ballester, P.; Buhr, C.; Jeong, K. S.; Jones, S.; Parris, K.; Williams, K.; Rebek, J., Jr. J. Am. Chem. Soc. 1989, 111, 1082-1090. (b) Williams, K.; Askew, B.; Ballester, P.; Buhr, C.; Jeong, K. S.; Jones, S.; Rebek, J., Jr. J. Am. Chem. Soc.1989, 111, 1090-1094.

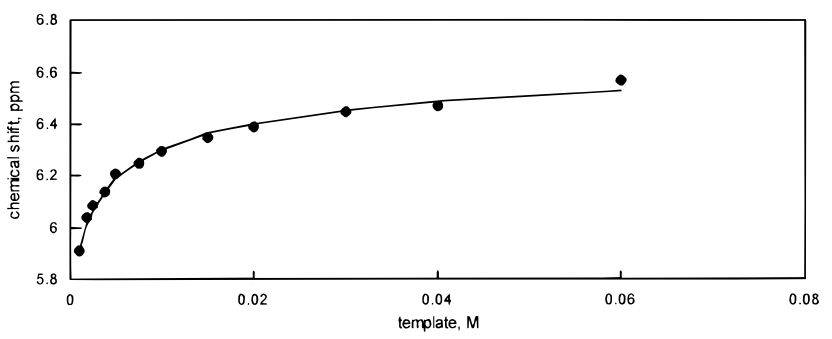

Figure 2. Dilution curve of template 3 in $\mathrm{CDCl}_{3}$ : experimental points and the theoretical curve.

The value of $100 \mathrm{M}^{-1}$ (corrected for statistical factors where appropriate) was subsequently used for all interactions between the same unrestricted hydrogen-bonding sites.

Dimerization of template $\mathbf{3}$ was studied in detail (see Figure 1). ${ }^{18}$ The general equilibrium scheme presented above was used to calculate the concentrations of the species T, TT, TTT, TTTT, $\mathrm{T}_{2}$, and $\mathrm{T}_{3}$ as a function of total template concentration. The observed chemical shift of the mixture is

$$
\delta_{\text {obsd }}=f_{\text {free }} \delta_{\text {free }}+f_{\text {lin }} \delta_{\text {lin }}+f_{\text {cyclic }} \delta_{\text {cyclic }}
$$

with

$$
\begin{gathered}
f_{\text {free }}=([\mathrm{T}]+[\mathrm{TT}]+[\mathrm{TTT}]+[\mathrm{TTTT}]) /\left[\mathrm{T}_{0}\right] \\
f_{\text {lin }}=\left([\mathrm{TT}]+2[\mathrm{TTT}]+3[\mathrm{TTTT}]+3\left[\mathrm{~T}_{3}\right]\right) /\left[\mathrm{T}_{0}\right] \\
f_{\text {cyclic }}=2\left[\mathrm{~T}_{2}\right] /\left[\mathrm{T}_{0}\right]
\end{gathered}
$$

The chemical shifts correspond to the free template T $\left(\delta_{\text {free }}\right)$, to the linear oligomers TT, TTT, and TTTT $\left(\delta_{\text {lin }}\right)$, and to the cyclic dimer $\mathrm{T}_{2}\left(\delta_{\text {cyclic }}\right)\left(\left[\mathrm{T}_{0}\right]\right.$ is the total template concentration). We assumed that the chemical shift of the cyclic trimer $\mathrm{T}_{3}$ is the same as in the linear oligomers. For the regression analysis, we assumed that $K_{8}=200 \mathrm{M}^{-1}, K_{12}=K_{18}=100 \mathrm{M}^{-1}$, and $K_{13}=0.1 K_{9}$. Subsequent multilinear regression analysis according to the equation for $\delta_{\text {obsd }}$ with $K_{9}$ and the three chemical shifts as variables gave a value of $0.3 \mathrm{M}^{-1}$ for $K_{9}$ and yielded reasonable values for the unknown chemical shifts: $\delta_{\text {free }}$ $=5.65,{ }^{20} \delta_{\text {lin }}=7.13$, and $\delta_{\text {cyclic }}=7.02$. Agreement between theory and experiment is very good (see Figure 2). This result implies that the formation of the cyclic dimer is an unfavorable process. Our calculations show that, at a 5-10 mM concentration of $\mathbf{3}$ (which is normally the case), $c a .41-30 \%$ of $\mathbf{3}$ exists

(18) Initially, we employed the Horman-Dreux algorithm and calculated a $K_{\mathrm{D}}$ value of $1.45 \times 10^{2} \mathrm{M}^{-1}$ from dilution experiments. This is somewhat lower than that found by Rebek et al. ${ }^{3}\left(6.3 \times 10^{2} \mathrm{M}^{-1}\right)$. At this stage, assuming that $K_{\mathrm{D}}=K_{6}=K_{8} K_{9}$ (see above) and $K_{8}=200 \mathrm{M}^{-1}$ (value of $100 \mathrm{M}^{-1}$ multiplied by a statistical factor of 2), one can conclude that the cyclization value itself is rather low; $K_{9}=0.73 \mathrm{M}^{-1}$ (or $3.15 \mathrm{M}^{-1}$ when Rebek's value is used). However, the Horman-Dreux algorithm gives only an approximate dimerization $K_{\mathrm{D}}$ value which characterizes the overall aggregation process including the formation of a cyclic dimer. When there are aggregates of more than two species, the Horman-Dreux algorithm cannot correctly describe the dimerization process. See: Horman, I.; Dreux, B. Helv. Chim. Acta 1984, 67, 754-764. Molecular mechanics calculations ${ }^{19}$ suggest that two molecules of $\mathbf{3}$, being quite flexible, fit much better in the linear than in the cyclic dimer structure.

(19) Brooks, B. R.; Bruccoleri, R. E.; Olafsen, B. D.; States, D. J.; Swaminathan, S.; Karplus, M. J. Comput. Chem. 1983, 4, 187. Quanta was bought from Molecular Simulations Inc., Burlington, MA.

(20) This $\delta_{\text {free }}$ value is in good agreement with $\delta$ values in $\mathrm{CDCl}_{3}$ for adenine $\mathrm{NH}_{2}$ protons published in the literature which range from 5.4 to 6.4 ppm. See, for example: Pieters, R. J.; Huc, I.; Rebek, J., Jr. Tetrahedron 1995, 51, 485-498. In the $N$-methylimide analog of $\mathbf{3}$, which is not able to dimerize, the $\mathrm{NH}_{2}$ signal of the adenine fragment is found at $5.69 \mathrm{ppm}$; see ref $3 b$. 


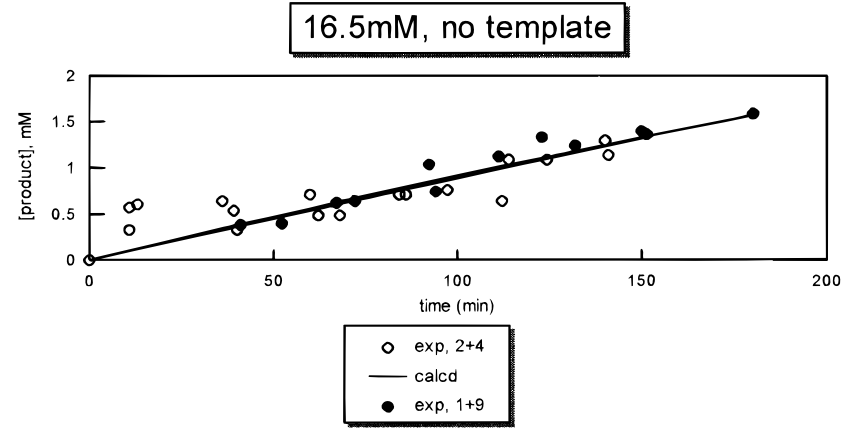

Figure 3. Generation of product for the reactions $\mathbf{2}+\mathbf{4}$ and $\mathbf{1}+\mathbf{9}$ as a function of time.

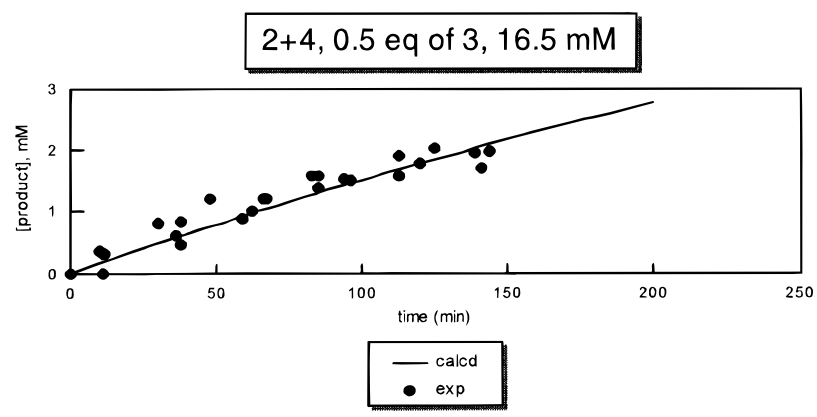

Figure 4. Generation of product for the reaction $2+4$ in the presence of 0.5 equiv of $\mathbf{3}$ as a function of time.

as the monomeric open form (T) along with $34-36 \%$ of $\mathbf{3} \cdot \mathbf{3}$ (TT), and $10-11 \%$ of cyclic dimer $\left(\mathrm{T}_{2}\right)$, linear trimer (TTT), etc.

The overall initial rate of reaction between $\mathrm{A}$ and $\mathrm{E}$ in the presence of template $\mathrm{T}$ can be given by

$$
\begin{aligned}
& \mathrm{d} P / \mathrm{d} t=k_{1}\left[\mathrm{~A}_{\mathrm{o}} \cdot \mathrm{E}_{\mathrm{o}}\right]+k_{2}[\mathrm{~A} \cdot \mathrm{E}]+k_{3}[\mathrm{~A} \cdot \mathrm{T} \cdot \mathrm{E}]+ \\
& k_{4}\left[\mathrm{E}_{\mathrm{o}}\right]\left(\left[\mathrm{A}_{\mathrm{o}}\right]-[\mathrm{A}]-[\mathrm{A} \cdot \mathrm{E}]\right)+k_{5}\left[\mathrm{~A}_{\mathrm{o}}\right]\left(\left[\mathrm{E}_{\mathrm{o}}\right]-[\mathrm{E}]-[\mathrm{A} \cdot \mathrm{E}]\right)
\end{aligned}
$$

A. Background Reaction. The rate constant $k_{1}=0.035$ $\mathrm{M}^{-1} \mathrm{~min}^{-1}$ for the background reaction could be obtained from normal second-order plots of $\mathbf{2}+\mathbf{4}$ and $\mathbf{1}+\mathbf{9}$ reactions (when measured at $16.5 \mathrm{mM}$ concentration) (Figure 3 ). This value is in fair agreement with Rebek's value of $k_{1}=0.023 \mathrm{M}^{-1} \mathrm{~min}^{-1}$ obtained for compound 2 and the $N$-methylated analog of $1 .^{3}$

B. Activated Bimolecular Reaction between $\mathbf{A} \cdot \mathbf{T}$ and $\mathbf{E}$. Reacting genuine A (possessing a hydrogen-bonding site) with a nonbinding analog of $\mathrm{E}$ in the presence of 0.5 equiv of template requires that $K_{1}=K_{3}=K_{4}=K_{5}=K_{7}=K_{11}=K_{14}$ $=K_{15}=K_{17}=0 \mathrm{M}^{-1}$ with $K_{2}=K_{10}=K_{12}=K_{16}=K_{18}=$ $100 \mathrm{M}^{-1}, K_{8}=200 \mathrm{M}^{-1}, K_{9}=0.3 \mathrm{M}^{-1}\left(K_{6}=60 \mathrm{M}^{-1}\right), K_{13}=$ $0.03 \mathrm{M}^{-1}$, and $k_{1}=0.035 \mathrm{M}^{-1} \mathrm{~min}^{-1}$. The formation of the product was calculated as a function of time, assuming that all equilibria are fast compared to the chemical reactions, for different values of $k_{4}$. From curve-fitting of the theoretical and experimental curves (Figure 4) over a time interval of $200 \mathrm{~min}$, the optimum value of $k_{4}=0.130 \mathrm{M}^{-1} \min ^{-1}$ was obtained. ${ }^{21}$

C. Bimolecular Reaction between $\mathbf{E} \cdot \mathbf{T}$ and $\mathbf{A}$. In the same way as described above, the reaction of a crippled A and the genuine ester $\mathrm{E}$ in the presence of template can be restricted by $K_{1}=K_{2}=K_{4}=K_{5}=K_{7}=K_{10}=K_{14}=K_{15}=K_{16}=0 \mathrm{M}^{-1}$ with $K_{3}=K_{11}=K_{12}=K_{17}=K_{18}=100 \mathrm{M}^{-1}, K_{8}=200 \mathrm{M}^{-1}$, $K_{9}=0.3 \mathrm{M}^{-1}\left(K_{6}=60 \mathrm{M}^{-1}\right), K_{13}=0.03 \mathrm{M}^{-1}$, and $k_{1}=0.035$ $\mathrm{M}^{-1} \mathrm{~min}^{-1}$. The fitting of theoretical and experimental conver-

(21) Theoretical curves were calculated on the basis of the model derived in the supporting information, on a normal PC using Lotus 123 software. Conversion as a function of time was calculated taking 4 min intervals.

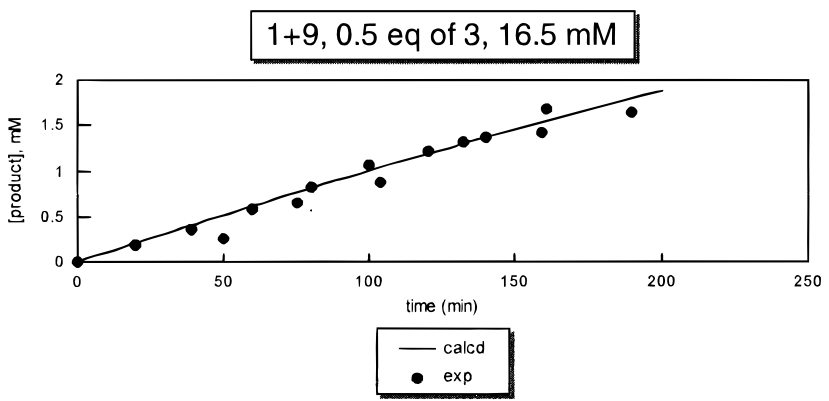

Figure 5. Generation of product for the reaction $\mathbf{1}+\mathbf{9}$ in the presence of 0.5 equiv of 3 as a function of time.

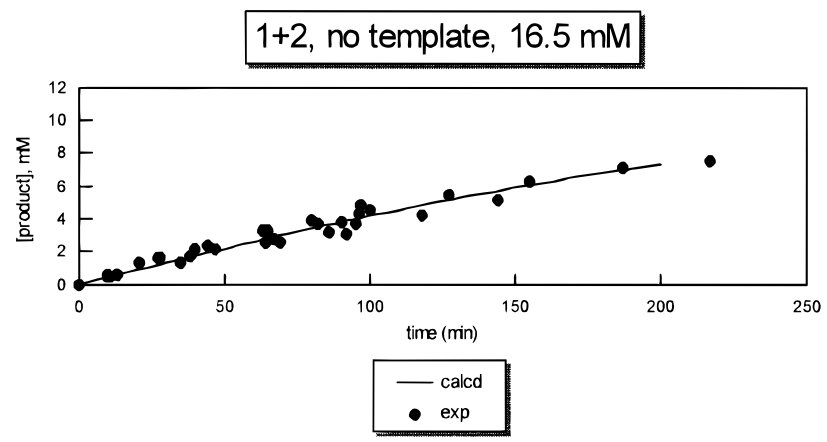

Figure 6. Generation of product for the reaction $\mathbf{1}+\mathbf{2}$ in the absence of template $\mathbf{3}$ as a function of time.

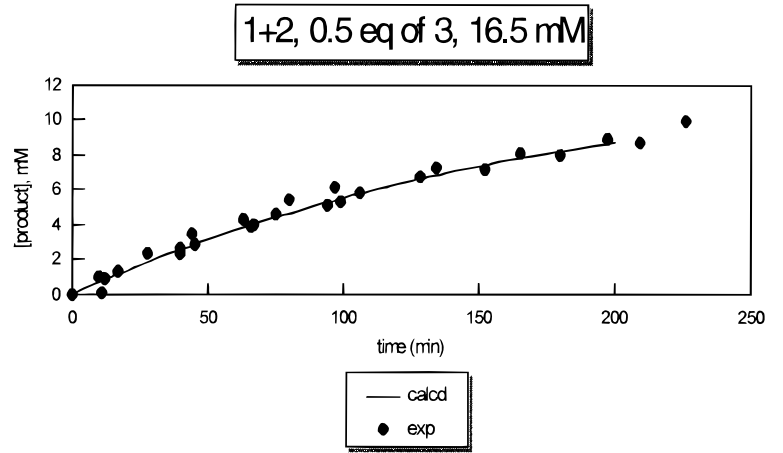

Figure 7. Generation of product for the reaction $\mathbf{1}+\mathbf{2}$ in the presence of 0.5 equiv of $\mathbf{3}$ as a function of time.

sion curves (Figure 5) over a time interval of 200 min gave an optimum value of $k_{5}=0.020 \mathrm{M}^{-1} \mathrm{~min}^{-1}$.

D. Preassociative Mechanism. Under conditions where components $\mathrm{A}$ and $\mathrm{E}$ react in the absence of template, the relevant equilibrium constants are $K_{1}=K_{2}=K_{3}=K_{4}=K_{5}=$ $K_{10}=K_{11}=K_{12}=K_{14}=K_{15}=K_{16}=K_{17}=K_{18}=100 \mathrm{M}^{-1}$, $K_{8}=200 \mathrm{M}^{-1}, K_{9}=0.3 \mathrm{M}^{-1}\left(K_{6}=60 \mathrm{M}^{-1}\right), K_{7}=10000$ $\mathrm{M}^{-2}$, and $K_{13}=0.03 \mathrm{M}^{-1}$ with the already determined rate constants $k_{1}=0.035 \mathrm{M}^{-1} \mathrm{~min}^{-1}, k_{4}=0.130 \mathrm{M}^{-1} \mathrm{~min}^{-1}$, and $k_{5}=0.020 \mathrm{M}^{-1} \mathrm{~min}^{-1}$. Curve-fitting of the theoretical and experimental conversion (200 min) curves (Figure 6) led to an optimum value of $k_{2}=0.0044 \mathrm{~min}^{-1}$.

E. Reaction of the Termolecular Complex. With the same parameter values as given above, and the newly determined reaction rate constant $k_{2}=0.0044 \mathrm{~min}^{-1}$, the theoretical conversion curves were calculated for the reaction between $\mathrm{A}$ and $\mathrm{E}$ in the presence of 0.5 equiv of template for various values of $k_{3}$. Least squares analysis gave an optimum value of $k_{3}=$ $0.030 \mathrm{~min}^{-1}$ (see Figure 7).

Predictions of Initial Rates Based on the Model. The model has been used to calculate the composition of the mixture of $\mathbf{1}$ and $\mathbf{2}$ with additives as a function of starting conditions 


\section{Chart 2}

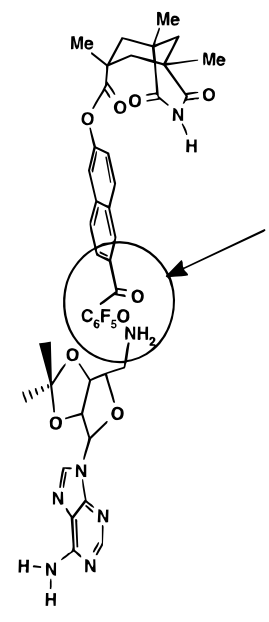

1

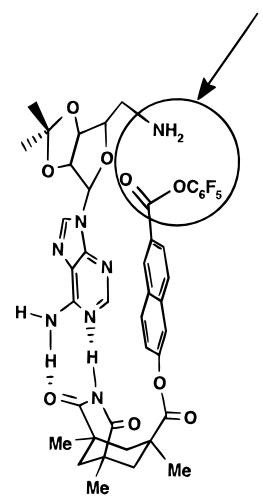

II

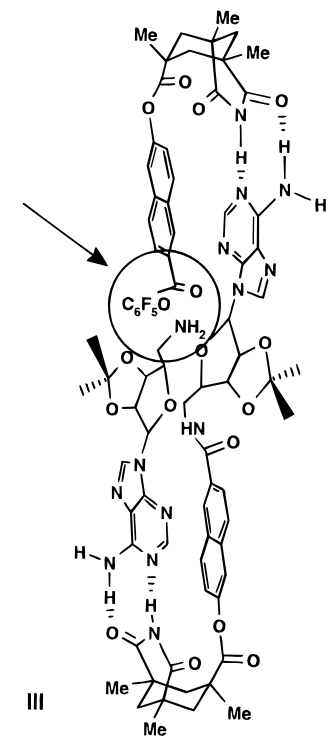

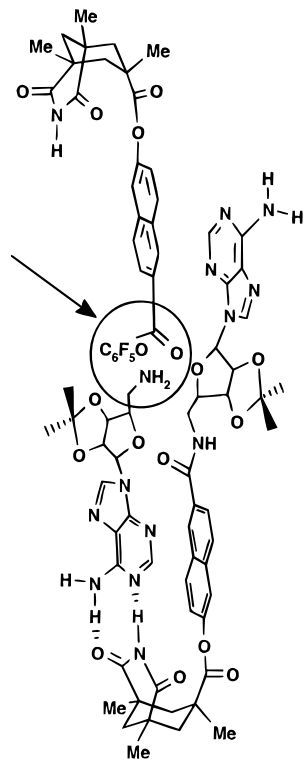

IV

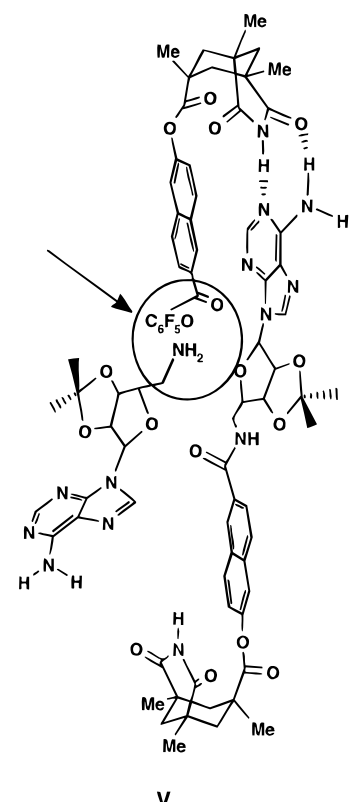

and time. In all cases, the above derived rate constants were used for the pathways depicted in Chart 2: background via I $\left(k_{1}=0.035 \mathrm{M}^{-1} \mathrm{~min}^{-1}\right)$, preassociative via complex II $\left(k_{2}=\right.$ $\left.0.0044 \mathrm{~min}^{-1}\right)$, termolecular via complex III $\left(k_{3}=0.030\right.$ $\left.\min ^{-1}\right)$, activated bimolecular via complex IV $\left(k_{4}=0.130 \mathrm{M}^{-1}\right.$ $\left.\min ^{-1}\right)$, and bimolecular via complex $\mathbf{V}\left(k_{5}=0.020 \mathrm{M}^{-1} \mathrm{~min}^{-1}\right)$.

In the case where both starting compounds $\mathrm{A}$ and $\mathrm{E}$ have a hydrogen-bonding site, which is the case for $\mathbf{2}$ and $\mathbf{1}$, the relevant equilibrium constants are (vide supra): $K_{1}=K_{2}=K_{3}=K_{4}=$ $K_{5}=K_{10}=K_{11}=K_{12}=K_{14}=K_{15}=K_{16}=K_{17}=K_{18}=100$ $\mathrm{M}^{-1}, K_{8}=200 \mathrm{M}^{-1}, K_{9}=0.3 \mathrm{M}^{-1}, K_{6}=60 \mathrm{M}^{-1}, K_{7}=10000$ $\mathrm{M}^{-2}$, and $K_{13}=0.03 \mathrm{M}^{-1}$. The calculated initial rates $(\mathrm{d} P /$ $\mathrm{d} t)_{t=0}$ and also the contribution (\%) of the different pathways via $\mathbf{I}-\mathbf{V}$ to the product formation are compiled in Table $2 .^{22}$ The results show the following. First of all, the model predicts the formation of product $\mathbf{3}$ as a function of time with a surprisingly good fit with the experimental data in the concentration range up to $30 \mathrm{mM}$ (see Table 2 and Figures 3-7). At $50 \mathrm{mM}$ the actual rates are higher than predicted (probably due to general base amide catalysis $\left.{ }^{7,8}\right)$. The relative contribution of the background reaction increases when the concentration increases at the expense of the preassociative mechanism. ${ }^{23}$ The template effect is highest at 8.25 and $16.5 \mathrm{mM}$ concentrations (up to $46 \%$ ). In the presence of an equimolar amount of template, the contribution of the termolecular complex III to the initial rate is in the range of $34 \%(1.67 \mathrm{mM})$ to $46 \%(16.5$ $\mathrm{mM})$. The contribution of the "amide catalysis" through the activated complex IV increases with increasing concentration. The template probably holds a complementary tetrahedral zwitterion in close proximity to the $\mathrm{NH}-\mathrm{C}(\mathrm{O})$ group which is

(22) We have tested the sensitivity of the results of our model as a function of the values for $K_{1}, K_{9}$, and $K_{6}$. When we take, e.g., values as published by Rebek $\left(K_{1}=60 \mathrm{M}^{-1}, K_{9}=3 \mathrm{M}^{-1}\right.$, and $\left.K_{6}=360 \mathrm{M}^{-1}\right)$, only small variations in $k_{2}-k_{5}$ are found. The relative contributions of $\mathbf{I}-\mathbf{V}$ to $(\mathrm{d} P / \mathrm{d} t)_{\text {calcd }}$ are $\leq 4 \%$. Estimated accuracies in the rate constants are as follows: $k_{1}=0.035 \pm 0.005 \mathrm{M}^{-1} \mathrm{~min}^{-1}, k_{2}=0.0044 \pm 0.0006 \mathrm{~min}^{-1}, k_{3}$ $=0.03 \pm 0.015 \mathrm{~min}^{-1}, k_{4}=0.13 \pm 0.03 \mathrm{M}^{-1} \mathrm{~min}^{-1}, k_{5}=0.02 \pm 0.02$ $\mathrm{M}^{-1} \mathrm{~min}^{-1}$. These accuracies of $k_{1}-k_{5}$ lead to upper and lower limits for the ratio $k_{3} / k_{2}$ of 3.0 and 10.7 , respectively.

(23) In the so-called "self-replicating molecules of second generation" Rebek et al. forced the reaction to the template-catalyzed mechanism by restraining the preassociative bimolecular pathway. See: Wintner, E. A.; Conn, M. M.; Rebek, J., Jr. J. Am. Chem. Soc. 1994, 116, 8877-8884.
Table 2. Calculated Initial Rates for Equimolar Amounts of $\mathbf{1}$ and $\mathbf{2}^{a}$

\begin{tabular}{|c|c|c|c|c|c|c|c|c|c|}
\hline \multirow[b]{2}{*}[2]{$_{\mathrm{o}}$} & \multirow[b]{2}{*}[\mathbf{1}]{$_{\mathrm{o}}$} & \multirow[b]{2}{*}[3]{$_{\mathrm{o}}$} & \multirow[b]{2}{*}{$(\mathrm{d} P / \mathrm{d} t)_{\text {calcd }}$} & \multirow[b]{2}{*}{$(\mathrm{d} P / \mathrm{d} t)_{\text {obsd }} b$} & \multicolumn{5}{|c|}{$\begin{array}{l}\text { contribution to } \\
\text { initial rate }(\%)\end{array}$} \\
\hline & & & & & I & II & III & IV & V \\
\hline 1.67 & 1.67 & & 0.10 & & 9.5 & 90.5 & 0.0 & 0.0 & 0.0 \\
\hline 1.67 & 1.67 & 1.67 & 0.14 & & 7.0 & 56.4 & 33.7 & 2.5 & 0.4 \\
\hline 2.2 & 2.2 & & 0.17 & & 10.1 & 89.9 & 0.0 & 0.0 & 0.0 \\
\hline 2.2 & 2.2 & 2.2 & 0.24 & & 7.2 & 52.5 & 36.8 & 3.0 & 0.5 \\
\hline 8.2 & 8.2 & & 1.5 & 1.4 & 15.8 & 84.2 & 0.0 & 0.0 & 0.0 \\
\hline 8.2 & 8.2 & 4.1 & 2.2 & 2.0 & 10.7 & 46.6 & 36.9 & 5.0 & 0.8 \\
\hline 8.2 & 8.2 & 8.2 & 2.5 & & 9.6 & 35.8 & 45.9 & 7.5 & 1.2 \\
\hline 16.5 & 16.5 & & 4.4 & $4.1^{c}$ & 21.9 & 78.1 & 0.0 & 0.0 & 0.0 \\
\hline 16.5 & 33.0 & & 6.9 & 8.2 & 27.7 & 72.3 & 0.0 & 0.0 & 0.0 \\
\hline 33.0 & 16.5 & & 6.9 & 7.9 & 27.7 & 72.3 & 0.0 & 0.0 & 0.0 \\
\hline 16.5 & 16.5 & 8.2 & 6.9 & $5.7^{c}$ & 13.7 & 38.3 & 38.5 & 8.3 & 1.3 \\
\hline 16.5 & 16.5 & 11.5 & 7.4 & 5.9 & 12.9 & 33.2 & 42.4 & 10.0 & 1.5 \\
\hline 16.5 & 16.5 & 16.5 & 7.8 & 6.2 & 12.2 & 28.1 & 45.7 & 12.2 & 1.9 \\
\hline 30 & 30 & & 10.6 & 12.9 & 29.7 & 70.3 & 0.0 & 0.0 & 0.0 \\
\hline 30 & 30 & 15 & 18.2 & & 17.4 & 31.1 & 37.2 & 12.5 & 1.9 \\
\hline 30 & 30 & 30 & 20.7 & 16.3 & 15.2 & 22.0 & 42.2 & 17.9 & 2.8 \\
\hline 50 & 50 & & 22.9 & 47.0 & 38.3 & 61.7 & 0.0 & 0.0 & 0.0 \\
\hline 50 & 50 & 25 & 41.3 & & 21.2 & 25.3 & 33.8 & 17.2 & 2.6 \\
\hline 50 & 50 & 50 & 48.1 & & 18.2 & 17.0 & 37.1 & 24.0 & 3.7 \\
\hline
\end{tabular}

${ }^{a}$ Concentrations in $\mathrm{mM}$; rates in $\mathrm{M} \cdot \mathrm{min}^{-1} \times 10^{5} .{ }^{b}$ Average rate over the first $100 \mathrm{~min} .{ }^{c}$ Used for parametrization.

involved in hydrogen bonding via a $\mathrm{C}=\mathrm{O} \cdot \cdots \mathrm{H}-\mathrm{N}^{+}$interaction (Figure 8). ${ }^{24}$ At $30 \mathrm{mM}$, it contributes almost 7 times as much to the overall initial rate than at $1.67 \mathrm{mM}$. In reactions where only the amine has a recognition site (e.g., $2+4)$ three of the five pathways are excluded: the preassociative pathway via II, the termolecular pathway via III, and the route via bimolecular complex $\mathbf{V}$. Table 3 shows that the relative contribution of the pathway via the only possible bimolecular complex IV increases with concentration ( $28 \%$ at $1.67 \mathrm{mM}$ to $59 \%$ at $30 \mathrm{mM}$ ).

When only the ester has a recognition site $($ e.g., $\mathbf{1}+\mathbf{9})$, the preassociative pathway via II, the termolecular pathway via III,

(24) MM calculations show that in the termolecular complex the distance between the zwitterionic $\mathrm{N}^{+}-\mathrm{H}$ and the template carbonyl $\mathrm{C}=\mathrm{O}$ group might be too large to form a hydrogen bond $(>4.5 \AA)$. Therefore, amide catalysis may be excluded in this case. Rebek et al. have recently published the similar conclusion; see ref 7. On the other hand, our MM calculation confirms hydrogen bonding within complex IV (e.g., amide catalysis); the distance between the zwitterionic $\mathrm{N}^{+}-\mathrm{H}$ and the template carbonyl $\mathrm{C}=\mathrm{O}$ group is $1.65 \AA$ in this case. 


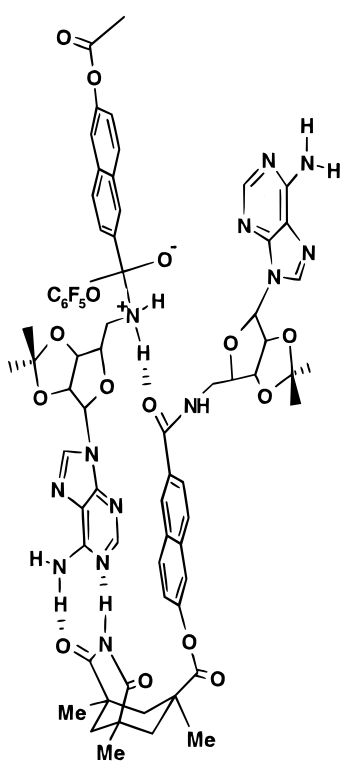

$2+4+3$

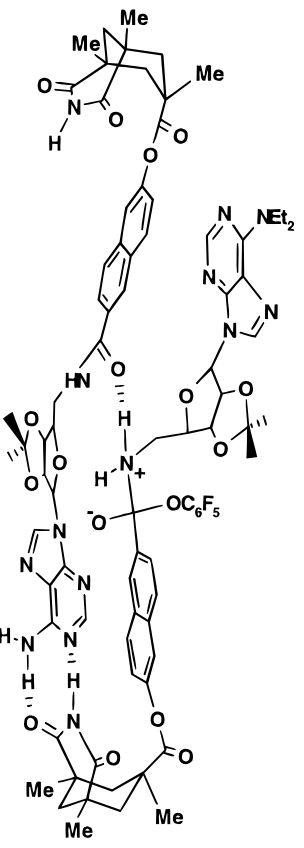

$1+9+3$

Figure 8. Possible tetrahedral zwitterionic intermediates $\mathbf{2}+\mathbf{4}+\mathbf{3}$ and $\mathbf{1}+\mathbf{9}+\mathbf{3}$ based on MM calculations. ${ }^{19}$ The distances between the amide carbonyl of $\mathbf{3}$ and the nitrogen proton of the tetrahedral intermediate are 1.65 and $2.12 \AA$, respectively.

Table 3. Calculated Initial Rates for Equimolar Amounts of 4 (1) and $2(9)^{a}$

\begin{tabular}{|c|c|c|c|c|c|c|c|c|c|}
\hline \multirow[b]{2}{*}[2]{$_{\circ}$} & \multirow[b]{2}{*}[4]{$_{o}$} & \multirow[b]{2}{*}[3]{$_{\mathrm{o}}$} & \multirow[b]{2}{*}{$(\mathrm{d} P / \mathrm{d} t)_{\text {calcd }}$} & \multirow[b]{2}{*}{$(\mathrm{d} P / \mathrm{d} t)_{\mathrm{obsd}}{ }^{b}$} & \multicolumn{5}{|c|}{$\begin{array}{l}\text { contribution to } \\
\text { initial rate }(\%)\end{array}$} \\
\hline & & & & & I & II & III & IV & $\mathbf{V}$ \\
\hline 1.67 & 1.67 & & 0.0095 & & 100 & 0.0 & 0.0 & 0.0 & 0.0 \\
\hline 1.67 & 1.67 & 1.67 & 0.0132 & & 72.4 & 0.0 & 0.0 & 27.6 & 0.0 \\
\hline 2.2 & 2.2 & & 0.0169 & & 100 & 0.0 & 0.0 & 0.0 & 0.0 \\
\hline 2.2 & 2.2 & 2.2 & 0.0247 & & 68.7 & 0.0 & 0.0 & 31.3 & 0.0 \\
\hline 8.2 & 8.2 & & 0.24 & & 100 & 0.0 & 0.0 & 0.0 & 0.0 \\
\hline 8.2 & 8.2 & 4.1 & 0.37 & & 63.9 & 0.0 & 0.0 & 36.1 & 0.0 \\
\hline 8.2 & 8.2 & 8.2 & 0.45 & & 52.2 & 0.0 & 0.0 & 47.9 & 0.0 \\
\hline 16.5 & 16.5 & & 0.95 & $0.6^{c}$ & 100 & 0.0 & 0.0 & 0.0 & 0.0 \\
\hline 16.5 & 33.0 & & 1.91 & & 100 & 0.0 & 0.0 & 0.0 & 0.0 \\
\hline 33.0 & 16.5 & & 1.91 & & 100 & 0.0 & 0.0 & 0.0 & 0.0 \\
\hline 16.5 & 16.5 & 8.2 & 1.66 & $1.6^{c}$ & 57.4 & 0.0 & 0.0 & 42.6 & 0.0 \\
\hline 16.5 & 16.5 & 11.5 & 1.85 & & 51.5 & 0.0 & 0.0 & 48.5 & 0.0 \\
\hline 16.5 & 16.5 & 16.5 & 2.09 & 1.8 & 45.6 & 0.0 & 0.0 & 54.4 & 0.0 \\
\hline 30 & 30 & & 3.15 & 3.3 & 100 & 0.0 & 0.0 & 0.0 & 0.0 \\
\hline 30 & 30 & 15 & 5.94 & & 53.0 & 0.0 & 0.0 & 47.0 & 0.0 \\
\hline 30 & 30 & 30 & 7.60 & 7.4 & 41.5 & 0.0 & 0.0 & 58.5 & 0.0 \\
\hline 50 & 50 & & 8.75 & & 100 & 0.0 & 0.0 & 0.0 & 0.0 \\
\hline 50 & 50 & 25 & 17.40 & & 50.4 & 0.0 & 0.0 & 49.6 & 0.0 \\
\hline \multirow[t]{2}{*}{50} & 50 & 50 & 22.60 & & 38.8 & 0.0 & 0.0 & 61.2 & 0.0 \\
\hline & & & & & \multicolumn{5}{|c|}{$\begin{array}{l}\text { contribution to } \\
\text { initial rate }(\%)\end{array}$} \\
\hline$[9]_{o}$ & {$[1]_{\mathrm{o}}$} & {$[3]_{\mathrm{o}}$} & $(\mathrm{d} P / \mathrm{d} t)_{\text {calcd }}$ & $(\mathrm{d} P / \mathrm{d} t)_{\mathrm{obsd}^{b}}$ & I & II & III & IV & $\mathbf{V}$ \\
\hline 16.5 & 16.5 & & 0.95 & 0.9 & 100.0 & 0.0 & 0.0 & 0.0 & 0.0 \\
\hline 16.5 & 16.5 & 8.25 & 1.06 & 1.0 & 89.8 & 0.0 & 0.0 & 0.0 & 10.2 \\
\hline
\end{tabular}

${ }^{a}$ Concentrations in $\mathrm{mM}$; rates in $\mathrm{M} \cdot \mathrm{min}^{-1} \times 10^{5} \cdot{ }^{b}$ Average rate over the first $100 \mathrm{~min} .{ }^{c}$ Used for parametrization.

and the route via bimolecular complex IV are excluded. Since $k_{5}$ is low, there is hardly any contribution to the pathway via $\mathbf{V}$ $(10 \%)$.

Comparison with the Work of the Rebek and Menger Groups. Although the experiments described in this paper are very similar, our approach is essentially different from those of Rebek and Menger. Rebek et al., ${ }^{3,6}$, focused on different template structures in order to prove the importance of the structure of their template (3) for self-replication. On the other hand, Menger et al. ${ }^{4,5}$ concentrated their work on reactions of crippled esters that lack a recognition site and that form amide products which are structurally different from 3 . They suggested that simple secondary amides act as catalysts, even at low concentration. ${ }^{4}$ It remains possible that at (very) high concentrations $(\geq 30 \mathrm{mM})$ nonspecific amide catalysis would play a role. ${ }^{7,8}$ However, such high concentrations are not the case in our work and in Rebek's experiments.

Crucial in the subsequent discussion is that both groups try to disprove the validity of the other experiments. However, experiments were never done under the same conditions with the same reactants and additives. As a consequence they generally interpret their own results correctly without disproving the conclusions of the other side.

The fact that concentrations of reactants and template(s) are often low in Rebek's original work and much higher in Menger's experiments is understandable because of the different analytical techniques used, but is very dangerous in a system that is governed by a multitude of equilibria among reactants, products, and additives.

Our approach was to describe this very complex problem in a (large) matrix of equilibria and reaction pathways. We have first determined all relevant association processes (and their constants) either by model experiments or by nonlinear regression analysis. Subsequently we have reduced all the reactions in the system to their most simple form and have experimentally determined the background $\left(k_{1}\right)$ and preassociative $\left(k_{2}\right)$ rate constants. In all those cases we had to assume one value for the equilibrium constants of all species with the same recognition site, and the same reactivity for free reactants and reactants complexed into linear associates. From two model reactions with crippled reactants we have obtained the rate constants $k_{4}$ and $k_{5}$ for the formation of the corresponding amides that proceed via the $A \cdot T+E^{\prime}$ and $E \cdot T+A^{\prime}$ pathways. Therefore, we have determined all rate constants except that of the selfreplicating termolecular pathway. This crucial rate constant $\left(k_{3}\right)$ is now simply obtained from the reaction between $\mathbf{1}$ and $\mathbf{2}$ in the presence of template $\mathbf{3}$ by subtracting the contributions of the other four pathways to the amount of product $\mathbf{3}$ which is formed.

The final test of our model is the correct prediction of product formation $v s$ time for different sets of experiments with Rebek's original system and Menger's model experiments (see Tables 2 and 3 and Figures 3-7).

Our results can be briefly summarized as follows:

(i) The experiments of Rebek et al. and Menger et al. are basically correct (but are in different concentration regimes).

(ii) We have identified five different pathways that lead to product (three are bimolecular and two are unimolecular). Their individual contributions to product formation are strongly concentration dependent.

(iii) In agreement with Menger et al., the bimolecular pathway $\mathrm{A} \cdot \mathrm{T}+\mathrm{E}\left(k_{4}\right)$ has been identified as a major contributor in reactions between 2 and $\mathbf{4}$. However, for reactions between 1 and $\mathbf{2}$ its contribution is small at concentrations $\leq 16.5 \mathrm{mM}$ and can be virtually neglected at the concentrations that were used by Rebek et al. Only at $50 \mathrm{mM}$ the contribution increases to $24 \%$.

(iv) The other bimolecular pathway $\mathrm{E} \cdot \mathrm{T}+\mathrm{A}\left(k_{5}\right)$, ignored by both Menger and Rebek, hardly contributes $(\leq 4 \%)$ over the entire concentration range $(1.67-50 \mathrm{mM})$. Both bimolecular pathways must have similar transition states or tetrahedral intermediates. Still there is a large difference in rate $\left(k_{4}=0.130\right.$ $\mathrm{M}^{-1} \mathrm{~min}^{-1}, k_{4} / k_{1}=3.7$, and $k_{5}=0.020 \mathrm{M}^{-1} \min ^{-1}, k_{5} / k_{1}=$ 
0.6). We can only conclude that in the reaction $\mathrm{A} \cdot \mathrm{T}+\mathrm{E}$ the amide moiety (or another structural element of $\mathrm{T}$ ) is precisely positioned for catalysis but that structural requirements are very critical for the $\mathrm{N}^{+}-\mathrm{H} \cdots \mathrm{O}=\mathrm{C}$ distance. Apparently, in the "mirror" reaction $\mathrm{E} \cdot \mathrm{T}+\mathrm{A}$ this specific stereochemistry cannot be met (see Figure 8). This means that an amide bond in the template cannot be the only source of catalysis.

(v) In agreement with Rebek et al., there is a kinetically favorable pathway via the termolecular complex $\mathrm{A} \cdot \mathrm{T} \cdot \mathrm{E}$ that contributes $34-46 \%$ to product formation (depending on concentration). When we compare the rates of both unimolecular reactions, e.g., the preassociative pathway $\left(k_{2}=0.0044\right.$ $\left.\min ^{-1}\right)$ and the termolecular pathway $\left(k_{3}=0.030 \mathrm{~min}^{-1}\right)$, the ratio $k_{3} / k_{2}$ is 6.8 ! With the accuracies in the values of $k_{1}-k_{5}$ (see ref 22) the lower and upper limits of the value of $k_{3} / k_{2}$ are 3.0 and 10.7, respectively. In our opinion this factor reflects the rate enhancement of the reaction between $\mathbf{1}$ and $\mathbf{2}$ when $\mathbf{3}$ is present (self-replication). Both reactants always have complementary binding sites, and when they associate this leads to reaction when the geometry of the associate allows the reactive groups a close proximity. When both reactants associate with the product 3 and subsequently react faster, this can be defined as genuine autocatalysis via self-replication. On the basis of our results, we can conclude that this is the case in the Rebek system. To what extent this pathway contributes to the total product formation depends on the concentrations of $\mathbf{1}, \mathbf{2}$, and $\mathbf{3}$ and on the rate constants $k_{1}-k_{5}$ for the five different pathways (see Table 2).

(vi) Crucial in the Rebek-Menger debate is the comparison of rate enhancement factors between reactions with and without template. Whereas Rebek et al. reported a $40-70 \%$ rate increase upon the addition of template $\mathbf{3}$ to a mixture of $\mathbf{1}$ and 2 (reactions that have both recognition sites), Menger et al. reported rate enhancements of $55 \%$ when 3 was added to a mixture of nonbinding ester $\mathbf{4}$ and amine 2. Our results show clearly how dangerous it is to use rate enhancement factors for comparison. When in model reactions at $16.5 \mathrm{mM}$ one of the reactants has no binding site (e.g. Menger's $2+4$ ), the absolute rate is a factor of ca. 7 lower than for the reaction $\mathbf{1}+\mathbf{2}$. When template $\mathbf{3}$ is added, only one of the bimolecular pathways $\left(k_{4}\right)$ can operate in addition to the background reaction $\left(k_{1}\right)$, but this still results in a rate enhancement of $167-200 \%$ (see Table 1). However, this cannot be compared with the rate enhancement when template $\mathbf{3}$ is added to the mixture of $\mathbf{1}$ and $\mathbf{2}$ that both have a recognition (binding) site. In that case the blank reaction is the result of two pathways, viz., background $\left(k_{1}\right)$ and preassociative $\left(k_{2}\right)$ mechanisms. In the presence of template $\mathbf{3}$ all five pathways $\left(k_{1}-k_{5}\right)$ participate. For Menger's reaction the rate enhancement factor is given by

$$
\left[k_{1}\left[\mathrm{~A}_{\mathrm{o}} \cdot \mathrm{E}_{\mathrm{o}}\right]+k_{4}\left[\mathrm{E}_{\mathrm{o}}\right]\left(\left[\mathrm{A}_{\mathrm{o}}\right]-[\mathrm{A}]-[\mathrm{A} \cdot \mathrm{E}]\right)\right] / k_{1}\left[\mathrm{~A}_{\mathrm{o}} \cdot \mathrm{E}_{\mathrm{o}}\right]
$$

In Rebek's reaction this rate enhancement factor is given by

$$
\begin{aligned}
& {\left[k_{1}\left[\mathrm{~A}_{\mathrm{o}} \cdot \mathrm{E}_{\mathrm{o}}\right]+\right.} k_{2}[\mathrm{~A} \cdot \mathrm{E}]+k_{3}[\mathrm{~A} \cdot \mathrm{T} \cdot \mathrm{E}]+ \\
& k_{4}\left[\mathrm{E}_{\mathrm{o}}\right]\left(\left[\mathrm{A}_{\mathrm{o}}\right]-[\mathrm{A}]-[\mathrm{A} \cdot \mathrm{E}]\right)+ \\
&\left.k_{5}\left[\mathrm{~A}_{\mathrm{o}}\right]\left(\left[\mathrm{E}_{\mathrm{o}}\right]-[\mathrm{E}]-[\mathrm{A} \cdot \mathrm{E}]\right)\right] /\left[k_{1}\left[\mathrm{~A}_{\mathrm{o}} \cdot \mathrm{E}_{\mathrm{o}}\right]+k_{2}[\mathrm{~A} \cdot \mathrm{E}]\right]
\end{aligned}
$$

(see also the supporting information). From these two ratios it is easy to see that in the two cases the reference reactions are different and rate enhancement factors cannot be compared. This is particularly true for these reactions where the contribution of $k_{2}[\mathrm{~A} \cdot \mathrm{E}]$ is much larger than of $k_{1}\left[\mathrm{~A}_{\mathrm{o}} \cdot \mathrm{E}_{\mathrm{o}}\right]$ (see Table 2).

Our general conclusion is that self-replication as defined by Rebek et al. ${ }^{3}$ operates in this system but that other pathways obscure the simple picture of a ternary complex as the only complex that leads to the enhancement. It would be interesting to analyze other self-replicating systems reported in the literature $^{1,2}$ in the same way because reactions via the bimolecular complexes, e.g., pathways via $\mathbf{I V}$ and $\mathbf{V}$, may also play a role there.

\section{Experimental Section}

${ }^{1} \mathrm{H},{ }^{13} \mathrm{C}$, and COSY NMR spectra were recorded in $\mathrm{CDCl}_{3}$ with TMS as the internal standard at $25{ }^{\circ} \mathrm{C}$ unless stated otherwise. $\mathrm{CDCl}_{3}$ was passed through $\mathrm{Al}_{2} \mathrm{O}_{3}$ and stored over molecular sieves (4 $\mathrm{A}$ ) before use. Ion fast atom bombardment (FAB) mass spectra were obtained with $m$-nitrobenzyl alcohol as a matrix. $\mathrm{CH}_{2} \mathrm{Cl}_{2}$ and $\mathrm{CHCl}_{3}$ were distilled from $\mathrm{CaCl}_{2}$ and stored over molecular sieves $(4 \AA)$. Hexanes refer to the fraction with bp $40-60^{\circ} \mathrm{C}$. Other chemicals were of reagent grade and were used without purification. Column chromatography was performed with silica gel (Merck; $0.040-0.063 \mathrm{~mm}$ ). All reactions were carried out in an argon atmosphere. Compounds $1-\mathbf{4}^{3,5,9}$ and $\mathbf{6}-\mathbf{8}^{7}$ were synthesized according to literature procedures and stored under an argon atmosphere. Compound $\mathbf{3}$ was also obtained in $92 \%$ yield by reaction of equimolecular amounts of pentafluorophenyl ester $\mathbf{1}$ and the $5^{\prime}$-aminoadenosine 2 and 4 equiv of $\mathrm{Et}_{3} \mathrm{~N}$ as a base in dry $\mathrm{CHCl}_{3}\left(24 \mathrm{~h}, 25^{\circ} \mathrm{C}\right)$. The organic layer was washed with $1 \mathrm{~N} \mathrm{HCl}_{\mathrm{aq}}$ and $\mathrm{H}_{2} \mathrm{O}(2 \times)$, dried over $\mathrm{MgSO}_{4}$, and evaporated to afford pure 3 .

Binding studies were performed in $\mathrm{CDCl}_{3}$ at $25^{\circ} \mathrm{C}$. An association constant value between acetyladenosine 16 and Kemp's ester 1 was determined at a constant concentration of $\mathbf{1 6}$ of $1 \mathrm{mM}$ and a varying concentration of 1 of $0.5-20 \mathrm{mM}$. The chemical shifts of the adenine $\mathrm{NH}_{2}$ signal and naphthalene protons were used as a probe. The $K_{\text {ass }}$ value was obtained with a nonlinear two-parameter fit of the chemical shift and the association constant. ${ }^{25}$ The results gave good fits for a typical 1:1 stoichiometry as could be concluded from the function values. ${ }^{25}$ Self-association experiments with template $\mathbf{3}$ were performed by following the chemical shift of the adenine $\mathrm{NH}_{2}$ signal of $\mathbf{3}$ at a concentration of $1-60 \mathrm{mM} .^{18}$

Aminolysis reactions were carried out by dissolving appropriate amounts of pentafluorophenyl ester and amine (and an additive if used) in $\mathrm{CDCl}_{3}$ containing 4 equiv of $\mathrm{Et}_{3} \mathrm{~N}$. $\mathrm{Et}_{3} \mathrm{~N}$ was freshly distilled over $\mathrm{NaOH}$ before use. Spectra were recorded after equal time intervals. Integrations were performed in the absolute intensity mode and using toluene as an internal standard. All measurements were performed at least twice, showing a good reproducibility. The results are collected in Table 1.

Molecular mechanics (MM) calculations of structures 1-16, their complexes, and the zwitterionic intermediates were performed with Quanta 3.3. The MM calculations were run with CHARMm 22.0, ${ }^{19}$ as implemented in the Quanta/CHARMm package. Energy minimizations (conjugate gradient) were carried out (steepest descents followed by adopted based Newton-Raphson) until the root mean square of the gradient was less than $0.01 \mathrm{kcal} \mathrm{M}^{-1} \AA$.

$\mathbf{2}^{\prime}, \mathbf{3}^{\prime}$-(1-Methylethylidene)- $N^{6}, N$-diethyladenosine (11). $p$-Toluenesulfonic acid monohydrate $(6.60 \mathrm{~g}, 35.0 \mathrm{mmol})$ was added to a magnetically-stirred suspension of 6-chloropurine riboside $\mathbf{1 0}$ (Aldrich) $(1.00 \mathrm{~g}, 3.5 \mathrm{mmol})$ in anhydrous acetone ${ }^{10}(150 \mathrm{~mL})$. The resulting solution was stirred for $1 \mathrm{~h}$ at $\mathrm{rt}$ and subsequently added to a vigorously stirred solution of $\mathrm{NaHCO}_{3}(6.7 \mathrm{~g}, 80 \mathrm{mmol})$ in ice and water $(80 \mathrm{~mL})$. The mixture was evaporated to dryness under reduced pressure, and the residual solid was extracted with acetone $(2 \times 100 \mathrm{~mL})$. The solvent was evaporated, and the residual oil was refluxed with diethylamine $(50 \mathrm{~mL})$ in EtOH $(150 \mathrm{~mL})$ overnight. Solvent was evaporated, and the residue was redissolved in hot water $(50 \mathrm{~mL})$. After $1 \mathrm{~h}$ the oil was separated and recrystallized from hexanes to afford colorless needles $(0.5 \mathrm{~g}, 39 \%)$ : $\mathrm{mp} 114{ }^{\circ} \mathrm{C}$ (hexanes); ${ }^{1} \mathrm{H}$ NMR $\delta 8.23$, $7.71(2 \mathrm{~s}, 2 \mathrm{H}), 7.0$ (br s, $1 \mathrm{H}), 5.79$ (d, $J=5.0 \mathrm{~Hz}, 1 \mathrm{H}), 5.24$ (t, $J=$ $5.0 \mathrm{~Hz}, 1 \mathrm{H}), 5.10(\mathrm{dd}, J=5.0 \mathrm{~Hz}, J=1.0 \mathrm{~Hz}, 1 \mathrm{H}), 4.51(\mathrm{~d}, J=1.0$ $\mathrm{Hz}, 1 \mathrm{H}), 4.0-3.7(\mathrm{~m}, 6 \mathrm{H}), 1.63,1.35(2 \mathrm{~s}, 6 \mathrm{H}), 1.26(\mathrm{t}, J=7.0 \mathrm{~Hz}$, $6 \mathrm{H}) ;{ }^{13} \mathrm{C}$ NMR (DMSO- $\left.d_{6}\right) \delta 153.1(\mathrm{~s}), 152.0(\mathrm{~d}), 149.5$ (s), 138.6 (d), 119.1, 113.0 (s), 89.7, 86.3, 83.3, 81.3 (d), 61.6, 42.4 (t), 27.0,

(25) de Boer, J. A. A.; Reinhoudt, D. N.; Harkema, S.; van Hummel, G. J.; de Jong, F. J. Am. Chem. Soc. 1982, 104, 4073-4076. 
25.0, 13.3 (q); MS-FAB $\mathrm{m} / \mathrm{z} 364.3$ [(M+H $)^{+}$, calcd 364.2]; HRMS-EI $\mathrm{m} / \mathrm{z} 363.1873\left(\mathrm{M}^{+}\right.$, calcd for $\mathrm{C}_{17} \mathrm{H}_{25} \mathrm{~N}_{5} \mathrm{O}_{4}$ 363.1907). Anal. Calcd for $\mathrm{C}_{17} \mathrm{H}_{25} \mathrm{~N}_{5} \mathrm{O}_{4}$ : C, 56.19; $\mathrm{H}, 6.93 ; \mathrm{N}, 19.27$. Found: C, 55.90; H, 6.78; $\mathrm{N}, 18.96$.

5'-(1,3-Dihydro-1,3-dioxo-2H-isoindol-2-yl)-2',3'-(1-methylethylidene)-5'-deoxy- $N^{6}, N$-diethyladenosine (12). Freshly distilled diethyl azodicarboxylate $(0.025 \mathrm{~g}, 0.14 \mathrm{mmol})$ was added to a magneticallystirred suspension of $2^{\prime}, 3^{\prime}$-(1-methylethylidene)- $N^{6}, N$-diethyladenosine (11) $(0.05 \mathrm{~g}, 0.14 \mathrm{mmol})$, phthalimide $(0.02 \mathrm{~g}, 0.14 \mathrm{mmol})$, and triphenylphosphine $(0.04 \mathrm{~g}, 0.14 \mathrm{mmol})$ in dry THF $(5 \mathrm{~mL}) .{ }^{9}$ After 1 $\mathrm{h}$ the solution was evaporated in vacuo. The mixture was purified by flash chromatography (silica gel, EtOAc $-\mathrm{CH}_{2} \mathrm{Cl}_{2}, 1: 1$ ) to give $\mathbf{1 2}$ as a colorless glass $(0.05 \mathrm{~g}, 74 \%)$ which was slightly contaminated with diethyl hydrazinedicarboxylate; ${ }^{1}{ }^{1} \mathrm{H}$ NMR $\delta 8.00,7.71(2 \mathrm{~s}, 2 \mathrm{H}), 8.8-$ $8.6(2 \mathrm{~m}, 4 \mathrm{H}), 5.95(\mathrm{~d}, J=1.8 \mathrm{~Hz}, 1 \mathrm{H}), 5.43(\mathrm{dd}, J=5.0 \mathrm{~Hz}, J=$ $1.8 \mathrm{~Hz}, 1 \mathrm{H}), 5.15-5.05(\mathrm{~m}, 1 \mathrm{H}), 4.4-4.3(\mathrm{~m}, 1 \mathrm{H}), 4.0-3.8(\mathrm{~m}, 6$ $\mathrm{H}), 1.50,1.29(2 \mathrm{~s}, 6 \mathrm{H}), 1.21(\mathrm{t}, J=7.0 \mathrm{~Hz}, 6 \mathrm{H}) ;{ }^{13} \mathrm{C}$ NMR $\delta 168.2$, 153.7 (s), 152.5 (d), 150.0 (s), 137.8, 134.0 (d), 132.0 (s), 123.3 (d), 120.0, 114.4 (s), 90.5, 84.9, 84.2, 82.6 (d), 43.1, 39.5 (t), 27.2, 25.5, 13.5 (q); MS-FAB $\mathrm{m} / z$ 493.9 [(M + H $)^{+}$, calcd 493.2]; HRMS-EI $\mathrm{m} / \mathrm{z}$ 492.2129 $\left(\mathrm{M}^{+}\right.$, calcd for $\left.\mathrm{C}_{25} \mathrm{H}_{28} \mathrm{~N}_{6} \mathrm{O}_{5} 492.2121\right)$.
$5^{\prime}$-Amino-2', $3^{\prime}$-(1-methylethylidene)-5' -deoxy- $N^{6}, N$-diethyladenosine (9). A mixture of $\mathbf{1 2}(0.49 \mathrm{~g}, 1 \mathrm{mmol})$ and hydrazine hydrate $(1.5 \mathrm{~mL})$ in EtOH $(10 \mathrm{~mL})$ was refluxed for $1 \mathrm{~h}$. The solution was evaporated to dryness in vacuo, and the residue was redissolved in $\mathrm{CH}_{2} \mathrm{Cl}_{2}(15 \mathrm{~mL})$, washed with $\mathrm{H}_{2} \mathrm{O}(3 \times 20 \mathrm{~mL})$, and dried over $\mathrm{MgSO}_{4}$. Solvent was evaporated, and the residue was dried in vacuo $\left(1 \mathrm{mmHg}, 75{ }^{\circ} \mathrm{C}\right)$ for $3 \mathrm{~h}$ to give 9 as a colorless oil $(0.30 \mathrm{~g}, 83 \%):{ }^{1} \mathrm{H}$ NMR $\delta 8.23,7.76(2 \mathrm{~s}, 2 \mathrm{H}), 5.96(\mathrm{~d}, J=3.0 \mathrm{~Hz}, 1 \mathrm{H}), 5.4-5.3(\mathrm{~m}$, $1 \mathrm{H}), 5.0-4.9(\mathrm{~m}, 1 \mathrm{H}), 4.15-4.05(\mathrm{~m}, 1 \mathrm{H}), 4.0-3.7(\mathrm{~m}, 4 \mathrm{H}), 3.0-$ $2.8(\mathrm{~m}, 2 \mathrm{H}), 1.55,1.31(2 \mathrm{~s}, 6 \mathrm{H}), 1.21(\mathrm{t}, J=7.0 \mathrm{~Hz}, 6 \mathrm{H}) ;{ }^{13} \mathrm{C} \mathrm{NMR}$ $\delta 153.8(\mathrm{~s}), 152.7(\mathrm{~d}), 150.0(\mathrm{~s}), 137.5(\mathrm{~d}), 120.3,114.4(\mathrm{~s}), 90.4,87.5$, 83.7, 81.8 (d), 43.9, 43.1 (t), 27.3, 25.4, 13.5 (q); MS-FAB m/z 363.1 $\left[(\mathrm{M}+\mathrm{H})^{+}\right.$, calcd 363.2]. HRMS-EI $\mathrm{m} / z, 362.2030\left(\mathrm{M}^{+}\right.$, calcd for $\mathrm{C}_{17} \mathrm{H}_{26} \mathrm{~N}_{6} \mathrm{O}_{3}$ 362.2066).

Supporting Information Available: A detailed kinetic scheme describing all equilibria and rate equations (6 pages). See any current masthead page for ordering and Internet access instructions.

JA960324G 